\title{
The Inflammasome NLRs in Immunity, Inflammation, and Associated Diseases
}

\author{
Beckley K. Davis, Haitao Wen, and Jenny P-Y. Ting \\ Department of Microbiology and Immunology, Lineberger Comprehensive Cancer Center, \\ University of North Carolina, Chapel Hill, North Carolina 27599
}

\begin{abstract}
Inflammasome activation leads to caspase-1 activation, which causes the maturation cleavage of pro-IL-1 $\beta$ and pro-IL-18. A subgroup of the NLR (nucleotide-binding domain, leucine-rich repeat containing) proteins are key mediators of the inflammasome. Studies of gene-deficient mice and cells have implicated NLR inflammasomes in a host of responses to a wide range of microbial pathogens, inflammatory diseases, cancer, and metabolic and autoimmune disorders. Determining exactly how the inflammasome is activated in these diseases and disease models remains a challenge. This review presents and integrates recent progress in the field.
\end{abstract}

\section{Keywords}

innate immunity; metabolic diseases; cancer; IL-1 $\beta$; caspase-1

\section{INTRODUCTION AND OVERVIEW}

Discrimination by the vertebrate host of molecular moieties derived from pathogenic insult requires the coordination of manifold systems of receptors and sensors that affect transcriptional and post-translational programs that are necessary for host defense and resolution of infection. Coordinately, pathogens have evolved mechanisms to counteract host surveillance and effector responses in a constant give and take in host-parasite interactions. In contrast, stimulation of the immune system in response to sterile insults can result in chronic debilitating conditions. Therefore, coordination of recognition, initiation, and elaboration of signals results in resolution, whereas dysregulation results in disease.

Germline encoded pattern-recognition receptors (PRRs) of the innate immune system recognize invariant molecular patterns that are conserved across Linnaean borders. The PRRs of the innate immune system fall into at least four distinct genetic and functional clades: Toll-like receptors (TLRs), C-type lectin receptors (CLRs), retinoic acid-inducible gene (RIG)-I-like receptors (RLRs), and the nucleotide-binding domain, leucine-rich repeat-

Copyright $@ 2011$ by Annual Reviews. All rights reserved jenny_ting@med.unc.edu, antigen@med.unc.edu, haiwen@med.unc.edu DISCLOSURE STATEMENT

The authors are not aware of any affiliations, memberships, funding, or financial holdings that might be perceived as affecting the objectivity of this review. 
containing (NBD-LRR) proteins (NLRs). The NLRs have not been shown to bind or receive any specific microbial product, but the members of the other families have been shown definitively to bind their cognate ligands. In fact, mounting evidence suggests that the NLRs serve as modulators of the TLR, RLR, and CLR signaling pathways.

\section{THE NLRs}

Genomic mining led to the discovery and characterization of the NLR gene family (reviewed in 1). Despite the fact that members of the NLR family share structural and some functional similarities with plant $\mathrm{R}$ proteins, the evolutionary history of these two families appears separate and convergent $(\underline{2}, \underline{3})$. Nonetheless, evidence that NLR-like genes are found in at least one nonvertebrate species, the echinoderm sea urchin, suggests that these genes have an ancient history (4), though representation is inconsistent given that other metazoan genomes such as Drosophila and Caenorhabditis do not have these genes.

NLRs are generally composed of three separate domains, all of which are found throughout metazoan evolution. At the amino terminus, NLRs either have a pyrin domain, a caspase recruitment domain, or a baculovirus inhibitory repeat domain. The exception is the NLRX1 protein, which has an $\mathrm{N}$ terminus that contains a domain that does not align well against any of these three domains, but it appears to have a similar three-dimensional fold. The Nterminal domain has been used as a structural subclassification for the NLR family and is supported by phylogenetic analysis $(\underline{2}, \underline{5})$. The central NBD or NACHT (nucleotide- $\underline{\text { binding }}$

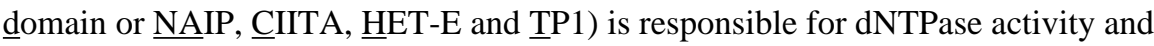
oligomerization. The NBD, in the presence of nucleotides, primarily ATP, is thought to form a signal receptive state. The $\mathrm{C}$ terminus of NLR proteins is composed of a manifold series of LRRs. All three of these domains are implicated in protein-protein interactions and networks. As such, several NLRs have been associated with large macromolecular complexes.

\section{THE INFLAMMASOME}

Activation of caspase-1 is regulated by the inflammasome, a large multimeric structure in the cytosol (므). Activation of caspase-1 leads to the processing of IL-1 $\beta$ and IL-18 as well as to the unconventional secretion of a subset of leaderless proteins which might facilitate tissue repair (7). This process is thought to be analogous to apoptosome formation in response to apoptotic stimuli. Indeed, inflammasome structures, as shown by nuclear magnetic resonance spectroscopy (NMR), have shown striking structural similarities to the apoptosome ( $\underline{8})$. A significant subset of NLRs can activate the inflammasome in vitro. Several studies have demonstrated that NLRP1, 2, 3, 6, 12, NLRC4, NOD2 when ectopically overexpressed with caspase-1, and ASC (apoptosis-associated speck-like protein containing a caspase recruitment domain) can facilitate activation of caspase- 1 and IL- $1 \beta$ processing $(\underline{6}, \underline{9}-\underline{-12})$. However, the in vivo role for inflammasome function has only been characterized for a minority of these proteins, for example, NLRP1, NLRP3, and NLRC4. It is unclear if the remaining NLRs act in a supporting or specialized manner during inflammasome assembly. AIM2, though not structurally related to the NLRs can also serve as a keystone in inflammasome activation. 


\section{THE NLRP3 INFLAMMASOME}

NLRP3 (also known as cryopyrin and NALP3) is expressed by myeloid cells and is upregulated in response to stimulation of macrophages with pathogen-associated molecule patterns (PAMPs) (13). The gene encodes an amino-terminal pyrin domain, a central NBD, and a C-terminal LRR (14). NLRP3 lacks a caspase recruitment domain (CARD) and cannot recruit procaspase-1 except in the presence of the adaptor molecule ASC. NLRP3 interacts with ASC via pyrin domain homophilic interactions. NLRP3 also interacts with CARD8 (also known as CARDINAL and TUCAN), but the role of CARD8 is not currently understood because its elimination in a human monocytic cell line has not altered inflammasome function (15). HSP90 and SGT1 have been shown to interact with NLRP3 LRRs to maintain an inactive but stabilized structure (16). The interaction of chaperones with NLRs is not specific for NLRP3, as it is for NLRC4, NOD2, NOD1, and NLRP12 (16-- 18$)$. In vitro ectopic expression systems have demonstrated that NLRP3 can activate caspase-1 in the presence of ASC (9). Activation of the NLRP3 inflammasome results in $\mathrm{IL}-1 \beta / \mathrm{IL}-18$ processing, and various conditions can induce forms of programmed inflammatory cell death.

\section{Activation of the NLRP3 Inflammasome}

The NLRP3 inflammasome is activated by a diverse series of endogenous and exogenous agonists (Figure 1); however, there is no evidence of direct ligand binding. This has led to the general hypothesis that NLRP3 senses changes in the cellular milieu. Activators of the NLRP3 inflammasome are divided into two separate categories: self and foreign.

\section{Self-Activators of the Inflammasome}

Genetic activation or predisposition for activation of the NLRP3 inflammasome is associated with cryopyrinopathies or cryopyrin-associated periodic fever syndromes (CAPS) (NLRP3 is formerly known as cryopyrin): FCAS (familial cold-induced autoinflammatory syndrome), MWS (Muckle-Wells syndrome), and NOMID/CINCA (neonatal onset

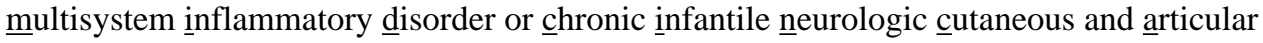
syndrome) (19). Despite the separate classifications, FCAS, MWS, and NOMID/CINCA represent a continuum of disease severity, with FCAS the most mild and NOMID/CINCA the most severe. All three of the cryopyrinopathies, despite phenotypic variability, are associated with periodic fevers and rashes, arthralgia, and conjunctivitis associated with neutrophil-dependent inflammation. NOMID/CINCA manifests a neurological involvement, including aseptic meningitis and deafness.

More than 70 separate inherited and de novo mutations have been identified. A preponderance of mutations in the gene is clustered in the NBD domain, although a small percentage is located in the LRR. Single mutations are associated with multiple clinical syndromes, suggesting either additional modifying loci or environmental factors (20) . This distribution might reflect a relaxed requirement of binding to ATP/dATP, a process that regulates assembly of the inflammasome (21). Indeed, PBMCs from patients with NOMID secrete significantly more spontaneous and induced IL-1 $\beta(\underline{22})$. Patient monocytes are also susceptible to spontaneous cell death associated with the release of proinflammatory 
mediators, thereby propagating the inflammatory response $(\underline{22}, \underline{23})$. Symptoms are abrogated with treatment with Anakinra and other IL-1 $\beta$-targeted therapies (20). Nonetheless, a cohort of patients with CAPS, especially NOMID patients, encode no mutations in NLRP3, suggesting additional loci involved in disease. Notwithstanding, these non-NLRP3 cryopyrinopathies respond similarly to IL-1 $\beta$ pathway inhibition.

To model these human diseases in mice, two groups generated knock-in mice with mutations associated with FCAS and MWS $(\underline{24}, \underline{25})$. These mice strains exhibited severe phenotypes, more than what was expected from the clinical manifestations seen with human patients. A common phenotype among all the strains was the development of erythema and abscesses, with marked inflammation that might model the urticarial rashes seen in human patients. Both groups demonstrated that expressing the mutant allele within the hematopoietic lineage replicated the phenotype. IL-1 $\beta$, tumor necrosis factor (TNF)- $\alpha$, and IL-17 were elevated at sites of inflammation. Pharmacological treatment of these mice with IL-1 $\beta$ pathway inhibitors or genetic crossing to an $I l 1 r^{-/-}$strain demonstrated a partial role for IL-1 $\beta$ in the onset and progression of disease seen in mice, further implicating IL-1 $\beta$ in the pathophysiology of disease. Myeloid cells derived from these mice do not spontaneously secrete IL-1 $\beta$ but instead have a lower threshold in response to PAMPs. Additionally, cells with the activating mutation do not require the addition of exogenous ATP. These data support the hypothesis that CAPS-associated mutations are gain-of-function mutants that affect myeloid-monocytic functions by lowering the threshold for IL-1 $\beta$ production.

The inflammasome can be activated by host-derived moieties that are typically crystalline or polymer in structure and are associated with danger, damage, or cell death. Self NLRP3 activators include ATP, monosodium urate (MSU), calcium pyrophosphate dihydrate (CPPD), cholesterol crystals, amyloid $\beta$, hyaluron, and possibly glucose (26). The NLRP3 inflammasome can sense the mislocalization of these endogenous molecules. For example, ATP, MSU, and CPPD are normally cytosolic constituents; however, if they are sensed in the extracellular environment, an inflammatory response is initiated (inside-out). Likewise, if extracellular cholesterol crystals, hyaluron, or amyloid $\beta$ are internalized (outside-in), a similar response is initiated.

Extracellular ATP, possibly derived from mitochondria (27), constitutes a damageassociated molecular pattern (DAMP) recognized by NLRP3. Exposure of LPS-primed macrophages to extracellular ATP activates caspase-1 in an NLRP3-dependent manner (28) that is mediated by the purinergic receptor P2X7 in combination with pannexin-1 (29). Uric acid is the by-product of homeostatic purine catabolism during normal cellular processes. Free uric acid derived from necrotic or infected cells and tissues is thought to form crystalline structures upon exposure to the extracellular space. The presence of ATP or MSU (as well as the related CPPD) activates the NLRP3 inflammasome $(\underline{28}, \underline{30})$ and contributes to several disease pathologies directly and indirectly.

Chronic hyperuricemia and deposition of MSU crystals within joints are characteristic of gout. The deposition within the joints induces a strong inflammatory response characterized by IL-1 $\beta$, TNF- $\alpha$, and IL-8 (31). Crystals are phagocytosed by resident macrophages via a process termed frustrated phagocytosis. The internalization of these crystals activates the 
NLRP3 inflammasome, which results in neutrophil-dependent inflammation of the joint and causes severe pain. Macrophages from $\mathrm{Nlrp}^{-/-}$mice do not activate caspase-1 in response to MSU in vitro. Injection of MSU crystals into the peritoneum of mice induces a strong neutrophil-dependent inflammatory response which depends on either NLRP3 or the IL-1 receptor (30). The role of IL-1 $\beta$ in human disease is underscored by the recent therapies aimed at this pathway. Most significantly, in clinical trials with patients suffering acute gout, treatment with Anakinra improved clinical symptoms (르).

Insoluble aggregates of amyloid $\beta$ are associated with neurodegenerative diseases such as Alzheimer's disease. The presence of extracellular and misfolded amyloid $\beta$ protein in senile plaques induces an inflammatory response by resident macrophages. Engulfment of these particles induces an inflammatory response that is NLRP3 dependent (3). The response is also dependent on the fibrillar amyoid $\beta$ because nonfibrillar amyloid $\beta$ does not induce a proinflammatory response in vitro. Injection of fibrillar amyloid $\beta$ into the brains of mice leads to an inflammatory response in vivo, suggesting that these misfolded protein aggregates contribute to disease pathology. However, the role of the inflammasome in such disease models of Alzheimer's has not been assessed.

Additional examples of inducers of sterile inflammation are cholesterol crystals and hyaluronan. Both can be sensed by surveilling macrophages as DAMPs. Rock and colleagues observed that cholesterol crystal deposition coincides with macrophage infiltration in arterial walls and within atherosclerotic plaques. Indeed, macrophages induced IL-1 $\beta$ in response to cholesterol crystals in an NLRP3-dependent manner (34). Hyaluronan is a glycosaminoglycan that is an essential component of the extracellular matrix but is also found in bacterial cell walls. It exists as a large polymer that can induce sterile inflammation during tissue injury. Purified high molecular weight hyaluronan can induce an NLRP3dependent IL- $\beta$ secretion in peritoneal macrophages (ㄷ5). Using a liquid nitrogen tissue injury model, Yamasaki et al. (35) demonstrated a modest decrease in IL- $1 \beta$ secretion in $\mathrm{Nlrp}^{-/-}$mice.

Cell death can be sensed by the innate immune system via the elaboration of DAMPs that are sensed by various pathways ( $\underline{36}$ ); however, the precise molecular moieties that are sensed are not clearly defined. During traumatic injuries such as fibrosis or ischemia, a cascade of NLRP3 agonists is released. Extracellular ATP, uric acid, P2X7 receptor, and IL-1 $\beta$ are involved in chronic and atopic lung inflammation (37--41), whereas ATP, P2X7 receptor, mitochondria, and hyaluron are associated with ischemia-reperfusion injury activation of the NLRP3 inflammasome (27). Using a bleomycin-induced lung injury in mice to model pulmonary fibrosis in humans, Riteau et al. (37) demonstrated a role for this pathway in airway inflammation and tissue remodeling. Additionally, bronchoalveolar lavage fluid from patients suffering from idiopathic lung fibrosis contained high levels of ATP, providing an in vivo correlate for human disease (37). A similar scenario is seen in allergic or asthmatic inflammation (41), where selective inhibition of the $\mathrm{P} 2 \mathrm{X} 7$ receptor or inhibition of uric acid formation in mice decreased the inflammatory pathology seen in allergic models ( $\underline{40})$. Targeting this pathway might represent a useful modality in treating asthmatic patients that are refractory to inhalative therapy with corticosteroids or $\beta 2$-agonists $(\underline{38})$. 


\section{Foreign Activators of the NLRP3 Inflammasome}

The NLRP3 inflammasome is also activated by many foreign molecules that are occupational or pathogenic in nature. Crystalline or particulate structures from exogenous sources also activate the NLRP3 inflammasome during sterile inflammation. Occupational exposure to asbestos or silica induces inflammation in the lungs and can lead to chronic and debilitating diseases. In response to these particles, macrophages secrete robust amounts of IL-1 $\beta$ and IL-18 via caspase-1 activation in an NLRP3-dependent manner (느-- $\underline{44})$. Nlrp $3^{-/-}$animals are less sensitive to both silica- and asbestos-induced lung injury as measured by infiltrating neutrophils and inflammatory cytokines. Recently, investigators demonstrated that the NLRP3 inflammasome can be activated by metal alloy particles derived from a prosthetic joint (노) and that this inflammation contributes to aseptic osteolysis (느).

In addition to occupational exposure to crystalline structures, people are subjected to routine vaccinations that contain adjuvants.. One particulate adjuvant often used in vaccine formulations for humans is alum. Alum's adjuvant effect is mediated in part by its ability to activate IL-1 $\beta$. Several groups have shown that alum-dependent caspase- 1 activation is mediated by NLRP3 (47-- $\underline{51}$ ). Nlrp $3^{-/}$mice demonstrate decreased vaccine efficacy as measured by antibody production. These data indicate that, by sensing alum, the NLRP3 inflammasome can affect the adaptive immune response. However, the finding is somewhat controversial. Although the NLRP3 inflammasome is involved in IgE induction by antigen and alum adjuvant $(\underline{48}, \underline{50})$, its involvement in $\operatorname{IgG1}$ induction is reported by some $(\underline{47}, \underline{48})$ but not by others (보-- $\underline{51})$. The reason for this discrepancy is not clear.

Environmental exposure to ultraviolent radiation and skin irritants in keratinocytes can activate the NLRP3 inflammasome $(\underline{52}, \underline{53})$. How these processes induce cellular damage and inflammation is unclear. The damage induced might activate the inflammasome indirectly, possibly by the release endogenous NLRP3 agonists or alternatively by disrupting the integument barrier, allowing exogenous bacterial moieties to be sensed.

Pathogens are robust activators of caspase- 1 and IL-1 $\beta / I L-18$ processing. Indeed, IL-1 $\beta /$ IL-18 are necessary in pathogen infections. Pathogens or PAMPs that gain access to the host cell cytosol can be sensed by resident NLRs. NLRP3 can sense bacterial, viral, and fungal pathogens that enter the cytosol, most likely via virulence factors, PAMPs, or DAMPs. Indeed, NLRP3 has been implicated in responses to the following bacteria: Staphylococcus aureus, Listeria monocytogenes, Klebsiella pneumoniae, Neisseria gonorrhoeae, Escherichia coli, Shigella flexneri, and Chlamydia spp. Additionally, NLRP3 is involved in the immune responses to adenovirus, influenza A, sendai, and vaccinia viruses and the fungi Candida albicans, Saccharomyces cerevisiae, and Aspergillus fumigatus. Attributing activation of the NLRP3 inflammasome to a single pathogen moiety or conversely attributing pathogen sensing to a single NLR locus are likely oversimplifications. Recent publications have illustrated the dynamic and cooperative role of multiple NLR responses to pathogens $(\underline{54}, \underline{55})$.

Nonetheless, several pore-forming toxins from bacteria have been shown to activate the NLRP3 inflammasome. Notably, hemolysins from Staphylococcus aureus (ㅁ6, $\underline{57})$, 


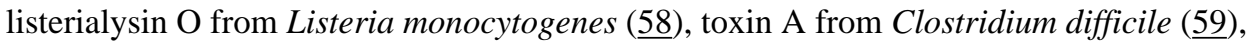
tetanolysin $\mathrm{O}$ from Clostridium tetani (으), and aerolysin from Aeromonas hydrophila ( $\underline{61})$ have all been shown to activate NLRP3. In certain cases, disease pathologies can be attributed to these toxins; for example, administration of toxin A from Clostridium can recapitulate the disease seen with whole bacteria..

A role for NLRs in viral immunity is emerging. Double-stranded RNA from influenza and sendai viruses and adenoviral DNA can stimulate the inflammasome in an NLRP3dependent fashion. During in vivo infection with low doses of influenza A, NLRP3 is dispensable for host survival (62); however, at high doses of influenza A, NLRP3 is central in recruiting inflammatory cells to the lungs $(\underline{15}, \underline{63})$. Nlrp $3^{-/-}$mice have increased mortality and morbidity during influenza infection that is associated with increased necrosis and collagen deposition (63). In addition to NLRP3 recognition of viral nucleic acids, poreformation and ion flux via the M2 channel of influenza A are necessary for the NLRP3 inflammasome activation, as demonstrated by a recent study (64). The NLRP3 inflammasome activation triggered by influenza virus involves many of the same pathways that are necessary for activation by DAMPs, suggesting a unifying pathway (15). The role of the NLRP3 inflammasome in response to DNA viruses is less documented. A role for NLRP3 in response to adenovirus, herpes virus, and vaccinia virus was suggested by in vitro experiments $(\underline{65}, \underline{66})$. In response to adenoviral DNA, herpes simplex virus, or modified vaccinia virus, the NLRP3 inflammasome was necessary for caspase-1 activation $(\underline{65}, \underline{66})$. However, NLRP3 likely plays a minor role, given that AIM2 has emerged as a bona fide cytosolic receptor for pathogenic DNA that activates an inflammasome (67).

The caspase-1 pathway is essential for host response to fungal pathogens ( $\underline{68})$. In response to Saccharomyces cerevisiae (69), Aspergillus fumigatus (70), and Candida albicans (71), NLRP3 is necessary for host survival and for the control of $C$. albicans dissemination in a mouse model of candidiasis (72). The response to C. albicans depends on the kinase activity of SYK ( $\underline{71})$ and possibly of hyphae (3). The mechanism by which SYK regulates NLRP3 activity is independent of its transcriptional regulation of $I l l \beta$. Interestingly, SYK is also involved in NLRP3-dependent activation in response to malarial hemozoin (74), although the in vivo relevance of NLRP3 in malarial infection or response to parasite extract or hemozoin has not been demonstrated $(\underline{75}, \underline{76})$.

\section{THE NLRC4 INFLAMMASOME}

NLRC4 is expressed predominantly in hematopoietic tissues and cells (12). The gene encodes an amino-terminal CARD, a central NBD domain, and C-terminal LRRs. It interacts directly with procaspase-1 via homotypic CARD interactions, which leads to the processing of caspase-1 in overexpression systems. Deletion of the LRR allows for dysregulated processing of caspase-1, presumably removing the autoinhibitory function of the LRR (12). The LRR of NLRC4 has also been shown to interact directly with HSP90 and SGT1 to form an inhibited but receptive oligomeric state (16). Activation of the NLRC4 inflammasome leads to IL-1 $\beta$ and IL-18 secretion and a rapid cell death, termed pyroptosis. 


\section{Activation of the NLRC4 Inflammasome}

Gene ablation experiments have demonstrated a role for NLRC4 in host defense against Salmonella, Shigella, Pseudomonas, and Legionella infections (77). During these bacterial infections, caspase- 1 activation leads to processing of IL- $1 \beta$ and IL-18, followed by a caspase-1-dependent cell death. Bone marrow-derived macrophages (BMDM) infected with Salmonella demonstrate a paucity of IL-1 $\beta$ and IL-18 secretion and are refractory to pathogen-induced cell death (77). Contrary to the in vitro effects seen in Salmonella-infected macrophages, mice infected with Salmonella are not more susceptible. Casp1 ${ }^{-/-}$mice, however, are clearly susceptible. This result suggests that additional NLRs may have a role in caspase-1 activation during in vivo infection with Salmonella.

Infection of mouse macrophages with Shigella demonstrates both an NLRC4- and NLRP3dependent activation of caspase- 1 and IL-1 $\beta / \mathrm{IL}-18$ processing and cell death $(\underline{22}, \underline{78})$. Interestingly, $\mathrm{NlrC4}^{-/-}$and $\mathrm{Caspl}^{-/-}$macrophages demonstrated an increase in autophagy in response to Shigella, suggesting that the inflammasome might negatively regulate pathogen-induced autophagy. The biological significance of inflammasome inhibition of autophagy might be a generalized mechanism, given that other NLRs affect autophagy (79, 80). In human transformed monocytic cell lines and in mouse macrophages, inflammasome response to a high dose of Shigella is controlled by NLRP3, reiterating the theme that multiple NLRs respond to the same bacteria but likely sense divergent bacterial products. Interestingly, the accompanying cell death associated with Shigella infection is independent of caspase-1 but dependent on cathepsin B (22).

Several groups have illustrated the role of NLRC4 in response to Pseudomonas infection $(\underline{81}, \underline{82})$. BMDM from $N \operatorname{lrc} 4^{-/}$mice show a similar decrease in caspase-1 activity, IL-1 $\beta /$ IL-18 secretion, and cell death to that seen with Salmonella. However, unlike mice infected with Salmonella, mice infected with Pseudomonas are more susceptible in both oral and peritoneal infection models, possibly because of an increased bacterial burden. Additionally, cell death associated with Pseudomonas is independent of NLRC4.

Legionella pneumophila also induces caspase-1 activation, IL-1ß/IL-18, and cell death in macrophages. These responses are mediated at least in part by NLRC4. Indeed, $\mathrm{NrC}^{-/-}$ mice do not secrete IL-1 $\beta$ or IL-18 or exhibit the rapid pronounced cell death seen in wildtype macrophages. In addition to cell death, NLRC4 has been implicated in phagosome maturation during Legionella infection. As a consequence, $\mathrm{NlrC}^{-/-}$macrophages are susceptible to bacteria replication. A related NLR protein, Naip5, has been genetically linked to Legionella replication in mice (83) and humans ( 144$)$ and has been shown to sense an additional epitope found within flagellin $(\underline{85}, \underline{86})$. This association coupled with the observation that NLRC4 can interact with NAIP5 in ectopic overexpression systems led researchers to investigate the cooperative role of these two proteins in Legionella infection. Indeed, restriction of Legionella replication relies on NLRC4 and NAIP5 (87). How these two proteins interact to affect Legionella growth is not currently understood, but NAIP5 is apparently not required for caspase- 1 activation in response to Salmonella, Pseudomonas, or Listeria. 
An NLRC4-dependent response to these pathogens requires ASC. ASC-deficient macrophages secrete significantly less caspase-1-dependent IL-1//IL-18 in response to Salmonella, Shigella, or Pseudomonas (77). However, ASC is not necessary for NLRC4dependent cell death $(\underline{77}, \underline{78}, \underline{81})$. This bifurcation point suggests that NLRC4 might utilize ASC in specific contexts, such as IL- $1 \beta$ processing, but not in others, such as cell death.

\section{Activators of the NLRC4 Inflammasome}

Intracellular flagellin was first shown to activate the NLRC4 inflammasome $(\underline{88}, \underline{89})$.

Additionally, Salmonella and Legionella mutant strains that do not express flagellin do not activate caspase-1, suggesting that NLRC4 is the cytosolic sentinel for flagellin. NLRC4dependent responses to flagellin depend on intact type III or IV secretion systems (T3SS or T4SS) (90). Together, these data suggest that flagellin gains entry to the host cytosol via T3SS or T4SS. Indeed, flagellin from Salmonella is injected into the host cytosol by T3SS; however, caspase-1 responses to Shigella are NLRC4-dependent, while Shigella does not express flagellin. In addition, some Pseudomonas mutants that lack flagellin activate caspase-1 in an NLRC4-dependent manner. A resolution to this paradox is supplied by a recent paper that showed that the rod protein components of the T3SS can serve as NLRC4 agonists (90). Rod proteins are highly conserved in bacteria, and as such recognition by NLRC4 would provide a generalized surveillance mechanism. It is proposed that rod proteins are injected into the cytosol of host cells via the T3SS, thus activating the NLRC4 inflammasome.

Similar to NLRP3, the mechanism by which the NLRC4 inflammasome senses these PAMPs is largely unknown. There has been no direct evidence of a ligand-receptor relationship between NLRC4 and flagellin or rod proteins. Initial experiments suggested that $\mathrm{K}^{+}$efflux was not a requisite for NLRC4-dependent inflammasome activation (91). However, one recent publication demonstrates that NLRC4 is inhibited by higher concentrations of extracellular $\mathrm{K}^{+}$levels than is NLRP3 (92) in response to nonflagellated Pseudomonas.

\section{THE NLRP1 INFLAMMASOME}

NLRP1 has less restricted expression than NLRP3 or NLRC4. It is expressed in adaptive immune cells and tissues as well as in nonhematopoeitic tissues (93). The human NLRP1 gene encodes an amino-terminal CARD, a central NACHT, LRR, FIIND, and a C-terminal CARD. This structural layout is unique to NLRP1. In cell-free lysates, NLRP1 interacts with caspase- 1 and -5 and possibly ASC to form a macromolecular complex (ㅁ). This complex is necessary for IL-1 $1 / \mathrm{IL}-18$ processing and pyroptosis. Additionally, NLRP1 interacts with caspase- 2 and -9 to facilitate cell death via the apoptosome (94). The physiological relevance of these interactions is unknown owing to the lack of an $\mathrm{NlrpI}^{-/-}$mouse.

\section{Activation of the NLRP1 Inflammasome}

Lethal toxin (LT) is considered the major virulence factor from Bacillus anthracis, given that treatment with the toxin alone is sufficient to cause disease. The observation that certain mouse strains susceptible to LT are linked to polymorphisms of Nlrplb led to speculation 
that it might sense the bacterial toxin. Human NLRP1 is encoded by a single locus that encodes an amino-terminal pyrin domain and an extended carboxy region that contains a CARD. There are three loci in the mouse genome, none of which encode an amino-terminal pyrin domain. Infection of a 129S1 strain or infection of mice expressing a transgene that encodes the sensitive Nlrplb allele from 129S1 with B. anthracis (도) induces the formation of a membrane-associated inflammasome that processes IL-1 $\beta / \mathrm{IL}-18$ and induces caspase-1dependent cell death (96). How IL-1 $\beta / \mathrm{IL}-18$ and macrophage cell death contribute to disease pathogenesis is controversial because some reports suggest that macrophage lysis contributes to pathology (97), whereas others indicate that it is protective to the host (98).

In biochemical reconstitution experiments with purified NLRP1, the absolute requirement for caspase-1 activation depends on NLRP1, procaspase-1, dNTPs, and muramyl dipeptide (MDP). ASC is not required but augments the enzymatic activity of the NLRP1 complex (8). Interestingly, NLRP1 can bind promiscuously to dNTPs in vitro, in contrast to other related AAA ATPases such as NLRP3, NLRC4, and NLRP12, which demonstrate exquisite specificity for ATP/dATP (21). Additionally, NMR structural analysis demonstrates pentaand heptameric complexes of NLRP1 that are structurally similar to the apoptosome. Deletion of the LRR allows for binding of dNTP and subsequent activation of caspase- 1 in the absence of MDP, suggesting that the LRR is autoinhibitory ( $\underline{8})$. Hydrolysis of dNTPs is required for oligomerization and activation of caspase-1, suggesting a two-step model ( $\underline{8})$. However, the role of MDP in vivo in NLRP1-dependent inflammasome activation is not clearly understood. Additionally, ectopically expressing NLRP1 and procaspase-1 in human epithelial cell lines confers sensitivity to LT. In vitro reconstitution experiments do not require ASC (99), nor does ASC associate with the NLRP1 inflammasome in mouse macrophage cell lines. How NLRP1 senses LT and MDP is not well defined. One study has shown that MDP together with purified NLRP1 activate the inflammasome (ㅇ); however, validation by others is needed. LT-dependent activation of caspase- 1 in macrophages depends on translocation of lethal factor into the cytosol, hence representing cytosolic sensing. Cell death and IL-1 $\beta$ secretion by NLRP1 depend on $\mathrm{K}^{+}$efflux and the lysosomal protein cathepsin $\mathrm{B}$ in a manner analogous to particulate uptake in NLRP3-dependent inflammasome activation.

\section{AIM2}

AIM2 (Absent in Melanoma-2), also known as PYHIN4, is an interferon inducible gene, the protein of which localizes to the cytosol. Initially, AIM2 was identified during a functional screen for tumor suppressor genes in melanoma (100). More recently several groups identified AIM2 as an inflammasome component by various modalities (101). The gene encodes an N-terminal pyrin domain and a C-terminal HIN200 domain. The pyrin domain of AIM2 is hypothesized to interact with pyrin domain of ASC. Caspase-1 is recruited to the complex to form a stable and competent inflammasome.

\section{Activation of the AIM2 inflammasome}

AIM2 as well as other members of the PYHIN (Pyrin and HIN200) family bind dsDNA via their HIN200 domain. AIM2 is the only member to encode a pyrin domain. Although not structurally nor evolutionarily related to the NLR proteins, AIM2 can facilitate 
inflammasome activation. Activation of the AIM2 inflammasome is mediated by DNA binding. The DNA:protein heteroduplex then recruits ASC and caspase-1. Similar to NLR inflammasomes the AIM2 inflammasome results in IL- $1 \beta$ and IL-18 secretion and cell death. AIM2 does not discriminate between the origins of DNA, instead it relies on its presence in the cytosol to initiate a response. The role of AIM2 has recently been suggested by in vivo studies using mice deficient in Aim2. Aim2 is hypothesized to play a role in responses to cytosolic bacteria and DNA viruses. Indeed in BMDM from Aim2 ${ }^{-/-}$there is a paucity IL-1 $\beta$ and IL-18 in response to certain DNA viruses such as vaccinia virus and mouse cytomegalovirus but not herpes simplex virus-1 (149-150). Additionally cell death associated with AIM2 specific viral infection is decreased. The decrease in IL-18 in response to mCMV led to decrease NK cell-dependent IFN- $\gamma$ secretion and increased viral titers (150). These results are consistent with the observation that replication of the viral genome occurs within the cytoplasm, coincident with AIM2 localization, and that the recognition of viral dsDNA is necessary for an effective immune response.

Francisella is a facultative intracellular pathogen that infects macrophages. Infection is mediated by the phagocytic pathway but the bacteria quickly escape the phagosome/ endosome compartment to replicate in the cytosol. Francisella infection is known to induce IL-1 $\beta$ and IL-18, however, the response is independent of NLRP3 and NLRC4 but dependent upon ASC. Subcutaneous Francisella infection of Aim2 ${ }^{-/-}$mice results in decreased IL-1 $\beta / \mathrm{IL}-18$ secretion and cell death, which led to increased mortality, therefore AIM2 appears to be the a sensor during Francisella infection (149). How DNA from intact bacteria is leached into the cytosol is currently unknown. However, phagosomal acidification might induce bacterial lysis of a small percentage of bacteria. A similar phenomenon has been documented with Listeria monocytogenes (104). In theory the DNA would have access to the cytosol (and hence AIM2) during the normal infection cycle of the bacteria.

\section{MODELS OF ACTIVATION OF THE INFLAMMASOMES}

How inflammasomes are activated is not clearly understood. Because of the diverse nature of PAMPs, DAMPs, and pathogens that activate inflammasomes, it is likely that multiple pathways exist. In addition, the transcriptional upregulation of limiting factors such as pro$I L 1 \beta$ and $-I L 18$, which constitute signal is, is a prerequisite for inflammasome activation. In addition to induced transcription of genes encoding pro-cytokines, activation of NLRP3 transcription is also induced by NF- $\kappa \mathrm{B}$ activators such as TLR ligands $(13,105,106)$. Three models have been put forth to explain mechanisms of inflammasome activation, once components of the inflammasome are available (Figure 2); however, no single model accounts for the various means by which inflammasomes are activated.

The first model posits that the generation of reactive oxygen species (ROS) by PAMPs and DAMPs can activate the NLRP3 inflammasome. This model is supported by the observation that many of the NLRP3-specific agonists induce ROS and that adding reactive oxygen compounds such as hydrogen peroxide can induce inflammasome formation. However, many biological pathways activate ROS, but not all activate inflammasomes. In addition, inhibition or scavenging of ROS can suppress NLRP3 inflammasome activation (107). 
However, the source of ROS remains a matter of debate, given that mice deficient in NADPH oxidase subunits and humans with chronic granulomatous disease (108) (characterized by defects in NADH-oxidase subunits) are competent for inflammasome activation. A recent paper demonstrated that TXNIP, a redox-sensitive protein, links the ROS pathway to the inflammasome (109). Therefore, the detailed mechanism by which ROS mediates NLRP3 activation requires further clarification (110).

The second model suggests that pore formation in the plasma membrane either by engagement of the $\mathrm{P} 2 \mathrm{X} 7$ receptor or by pore-forming toxins facilitates the efflux of $\mathrm{K}^{+}$and the possible influx of small DAMPs or PAMPs. Potassium efflux appears to be a common initiator for the inflammasome, as all three NLR inflammasomes are inhibited by hyperosmotic extracellular $\mathrm{K}^{+}$, albeit to different degrees. For example, the NLRP1 inflammasome can form spontaneously in the presence of hypoosmotic $\mathrm{K}^{+}$levels during lysis. Additionally, activation of the NLRP1 inflammasome by anthrax LT is inhibited by hyperosmotic extracellular $\mathrm{K}^{+}$. Interestingly, the T3SS that injects virulence factors such as flagellin and rod protein monomers (NLRC4 agonists) into the host cytosol might serve as a leaky channel for $\mathrm{K}^{+}$efflux.

A third model speculates that inflammasomes are activated in response to lysosomal damage, specifically cathepsin B leakage. Pharmacological inhibition of cathepsin B has been shown to inhibit inflammasome activation in response to DAMP stimulation. Mice deficient in cathepsin B are only partially impaired in inflammasome activation in response to some NLRP3 agonists. These data suggest either off-target effects of the inhibitor or genetic redundancy of the cathepsins. Indeed, either cathepsin B- or L-deficiency decreased inflammasome activation in response to cholesterol crystals in vivo. Future research will need to determine whether these pathways act in concert or independently in stimulationdependent contexts.

\section{INHIBITION OF THE INFLAMMASOME BY HOST AND MICROBES}

Inhibition of inflammation (Figure 3) by the host or pathogen is a common mechanism to limit damage or to facilitate infection. Autoinhibition of the inflammasome is a key element in limiting aberrant inflammatory responses to sterile insults and to cell death. The heterogeneity of the NLR isoform expression allows for intra-allelic inhibition of responses. To date, investigators have found that most NLRs exhibit alternative splicing to generate isotypic variants. ASC has recently been shown to have multiple isoforms, one of which appears to have inhibitory functions on caspase-1 activation (111). For example, NLRP1 and NOD2 are alternatively spliced $(\underline{94}, 112)$. The significance of these isoforms is not currently understood, but there is some evidence that they can serve as either positive, negative, or neoregulators of function to their full-length isoforms.

Outside of possible intra-allelic suppression of the inflammasome, the vertebrate host encodes several putative dominant-negative regulators of inflammasome activity. The pyrinonly proteins (POPs) and the CARD-only proteins (COPs) are two examples. The POPs are encoded by two loci in humans, $c P O P 1$ and $c P O P 2$. As the name implies, by virtue of having a pyrin domain these proteins can squelch ASC, thereby inhibiting ASC-dependent 
processes (113). COPs are hypothesized to function in manner analogous to that of POPs. They are encoded by four loci, ICEBERG, INCA, COP, and CASP12, on human chromosome 11. These proteins serve as decoy proteins for caspase-1 (113). For example, ICEBERG is induced by activation in monocytic cells to provide a brake for pathogeninduced caspase- 1 activation. The $M E F V$ encodes the pyrin protein, which is associated with familial Mediterranean fever (FMF). Putative loss-of-function mutations in this gene are associated with autoinflammatory fevers such as FMF in humans, and mice deficient in $M e f v$ are hypersensitive to LPS by secreting excess IL-1 $\beta$ (114).

The mechanism of action of pyrin is not well defined. Depending on the system, pyrin can act as either a positive or negative regulator of the inflammasome. One model proposes that pyrin via homotypic pyrin domain interactions with ASC can inhibit inflammasome oligomerization. Additionally, the B30.2 domain of pyrin, which is the location of many FMF-associated mutations, has been shown to interact directly with the catalytic domain of caspase-1 to prevent autoactivation (115). An opposing model based on biochemical data suggests that pyrin activates the inflammasome $(116,117)$. The role of pyrin in IL-1 $\beta$ regulation is supported by both models; however, the molecular mechanisms that mediate pyrin-dependent IL-1 $\beta$ regulation remain elusive. Serpin proteinase inhibitor 9 transcription is induced by IL-1 $\beta$. Upon induction, it binds to caspase- 1 and granzyme $\mathrm{B}$ to inhibit proteolysis (118). The Bcl-2 family members Bcl-2 and Bcl-xL, which are prototypic antiapoptotic proteins, have been shown to specifically interact with NLRP1 to inhibit ATP binding and subsequent oligomerization (119). These examples of cell autonomous inhibition provide evidence that the host has evolved multiple mechanisms to inhibit inflammation. An intriguing study demonstrated paracrine inhibition of both NLRP1 and NLRP3 inflammasomes by mouse effector and memory CD4 T cells in vivo. In vitro suppression was mediated by TNF family ligands such as CD40L (120); however, the mechanism of inhibition is currently not understood.

Pathogen-encoded inhibitors of the inflammasome are found in several different types of virus and bacteria and are reviewed in detail elsewhere (121). Members of the poxvirus family encode several examples of inhibitors of the host immune response. The prototypic viral inhibitor of the inflammasome is cytokine response modifier A, CrmA. CrmA is related to mammalian serpin proteins and acts as a specific inhibitor of caspase-1 (122). The mechanism of inhibition may reflect the ability of CrmA to covalently bind to the p20 subunit of caspase- 1 and inhibit the assembly of the active tetrameric caspase- 1 enzyme (123). Additional poxviruses, such as vaccinia and myxoma viruses as well as ectromelia virus express CrmA orthologs. Vaccinia virus encodes B13R, which shares $92 \%$ amino acid identity with CrmA. B13R has been shown to inhibit caspase-1 activation and IL-1 $\beta$ secretion (124). Myxoma and Shope fibroma viruses target ASC. The myxoma virus M013L protein is an essential viral protein that targets both the inflammasome and NF- $\kappa \mathrm{B}$ pathways. Loss of M013L results in attenuated virulence, associated with a more robust innate immune response. M013L binds to ASC to prevent inflammasome formation. Additionally M013L can interact with NF- $\kappa \mathrm{B}$ to inhibit transcription of proinflammatory cytokines IL-1 $\beta$, TNF- $\alpha$, IL-6, and CCL2 $(125,126)$. The Shope fibroma virus protein 
gp013L can inhibit IL-1 $\beta$ secretion in an in vitro reconstituted inflammasome. Additionally, overexpressed gp013L can inhibit NF- $\kappa \mathrm{B}-$ dependent transcription of cytokine genes (127).

$N S 1$, one of the ten encoded influenza viral genes, is a nonstructural protein that is critical for evasion of cytosolic host immune responses. The NS1 protein has pleiotrophic functions in inhibiting different immune pathways. In particular, viruses expressing mutations in the RNA-binding domain induce significantly more active caspase- 1 and secrete more IL-1 $\beta$ and IL-18 in human macrophages and display decreased virulence in vivo (128).

Baculovirus can inhibit caspase-1 via a p35-dependent mechanism. In an ectopic overexpression system, addition of $\mathrm{p} 35$ reduced IL- $1 \beta$ processing. Additionally, purified p35 was shown to retard caspase- 1 activity (129). The ability of p35 to inhibit caspase- 1 might be attributable to its ability to inhibit a range of initiator caspases by virtue of being a promiscuous substrate.

Bacterial inhibition of the inflammasome has been demonstrated by Yersinia, Pseudomonas, and Mycobacterium spp. Yersinia enterocolitica infection activates both the NLRP3 and NLRC4 inflammasomes (130). Yersinia encodes a family of outer proteins (Yops) that are injected into the host cytosol by T3SS. These proteins manipulate several key host responses. YopE, YopT, and YopK inhibit inflammasome activity $(130,131)$, and YopP inhibits NF- $\kappa \mathrm{B}$-dependent $I L-1 \beta$ transcription. Yersinia strains deficient in YopE, YopP, or YopT induce more robust IL- $1 \beta$ secretion during infection of mouse macrophage cell lines, whereas strains deficient in YopK are defective in bacterial clearance in vivo. The mechanism of inhibition of these proteins requires further study.

Pseudomonas aeruginosa is a potent activator of the NLRC4 inflammasome. This activation is mediated by flagellin-dependent and -independent mechanisms. The PA103 strain fails to induce robust IL- $1 \beta$ secretion in vivo. Sutterwala et al. (132) demonstrate that ExoU is responsible for this phenotype. An isogenic strain deficient in ExoU induces robust IL-1 $\beta$ (132). Although the mechanism by which ExoU inhibits the inflammasome is not currently understood, the phospholipase activity of ExoU is necessary for inflammasome inhibition.

The role of IL-1 $\beta$ in mycobacterial infections has recently been investigated. The mechanism by which IL-1 $\beta$ is activated during mycobacterial infection remains controversial as $\mathrm{Casp1}^{-/}$mice secrete equivalent amounts of IL-1 $\beta$ in vivo and have an increased mean survival time relative to IL-1 $\beta$-deficient animals (133). However, siRNA silencing of NLRP3 and ASC, in a human transformed cell line, results in diminished caspase- 1 activation and IL-1 $\beta$ secretion (134). The BCG strain of Mycobacterium tuberculosis encodes $\mathrm{Zmpl}$, a $\mathrm{Zn}^{2+}$ metalloprotease, and suppresses inflammasome function, and strains deficient in this gene are attenuated in their ability to inhibit caspase-1. Zmp1 suppression is not limited to BCG; it also acts across multiple NLRP3 agonists (135).

Francisella tularensis does not provoke a substantial proinflammatory response, unlike other gram-negative bacterial pathogens. The live vaccine strain of Francisella tularensis encodes two loci that inhibit inflammasome activation: ripA and $m v i N(136,137)$. Although the function of RipA is unknown, it can inhibit the MAPK pathway as well. MviN is a 
flippase that inhibits caspase-1 activation in an AIM2-dependent manner. The mechanisms by which these proteins inhibit inflammation are not well understood.

Streptococcus pneumoniae expresses pneumolysin, a pore-forming exotoxin. Strains deficient in pneumolysin have decreased virulence in mice, and pneumolysin has been shown to induce IL-1 $\beta$ and TNF- $\alpha$ in human mononuclear cells, possibly in a similar mechanism to other pore-forming toxins. It is noteworthy that during infection of human dendritic cells (DCs) with pneumolysin-deficient S. pneumoniae, caspase-1 activation is decreased, and, paradoxically, secretion of IL- $1 \beta$ is increased, suggesting a dynamic role for pneumolysin in IL-1 $\beta$ maturation (138). Caspase-1-independent activation of IL- $1 \beta$ has been described. However, the role of caspase-1-independent IL-1 $\beta$ production in vivo is poorly understood.

Overall, the host-pathogen interactome is dynamic in nature. Viruses have co-opted vertebrate genes and use them to circumvent the immune system. Bacteria have evolved elaborate mechanisms as well. The specific targeting of the inflammasome by pathogens underscores its importance in innate immunity.

\section{THE INFLAMMASOME IN METABOLIC DISORDERS AND CANCER}

\section{The NLRP3 Inflammasome and Metabolic Disorders}

The incidence of metabolic disorders such as obesity, type 2 diabetes mellitus (T2DM), and atherosclerosis has increased dramatically during recent decades, and these diseases constitute serious threats to human health. According to estimates from the World Health Organization (WHO), more than one billion adults worldwide are overweight, and 300 million of them are clinically obese (139). Furthermore, estimates suggest that T2DM will affect at least 350 million people by 2030 (140). During the past decade, it has become clear that chronic inflammation is a key predictor of metabolic disorders. For example, obesity is associated with upregulated cytokine production and activation of inflammatory signaling pathways (141). TNF, interleukins, and cytokine-like proteins known as adipokines have been linked to the development of insulin resistance associated with T2DM (142). Atherosclerosis has also been associated with chronic inflammation. Accumulation of immune cells and cytokine production are hallmarks of atherosclerotic plaques (143).

IL- $1 \beta$ is one of the proinflammatory cytokines involved in the pathogenesis of metabolic disorders. For example, prolonged IL-1 $\beta$ treatment reduces glucose transporter type 4 (GLUT4) expression and translocation to the plasma membrane in 3T3-L1 adipocytes and human adipocytes, which leads to a decreased insulin-stimulated glucose uptake and lipogenesis (144). IL-1 $\beta$ has also been implicated as an effector molecule involved in inflammation-promoted $\beta$-cell destruction leading to type 1 diabetes mellitus (T1DM) (145). High levels of glucose induces IL-1 $\beta$ secretion in vitro and promotes functional impairment and apoptosis of $\beta$-cells in an autocrine manner (109). In Apoe ${ }^{-/-}$mice that spontaneously develop atherosclerosis owing to hypercholesterolemia, IL-1 $\beta$ deficiency results in an attenuated development of atherosclerotic lesions, indicating that IL-1 $\beta$ plays an essential role in the pathogenesis of atherosclerosis (146). 
Findings from experimental studies suggest that IL-1 $\beta$ blockade may serve as a therapeutic regimen for metabolic diseases. Indeed, two recent clinical studies reported protective roles for either IL-1 receptor antagonist (IL-1ra) or IL-1 $\beta$ antibody in treating T2DM $(145,147)$. In a double-blind, parallel-group trial involving 70 patients with T2DM, Anakinra improved glycemia and $\beta$-cell secretory function and reduced markers of systemic inflammation (147). Another study reported that a single injection of anti-IL-1 $\beta$ antibody could improve insulin secretion (145). In summary, both clinical and experimental findings suggest that IL-1 $\beta$ impairs insulin signaling and induces the development and/or maintenance of insulin resistance.

Despite the extensive investigation of the role of IL-1 $\beta$ in metabolic diseases, the mechanisms whereby IL- $1 \beta$ is generated and released during metabolic stress conditions remains elusive. Two recent studies reported high level of glucose (109) and islet amyloid polypeptide (IAPP) (110) as key inducer of IL-1 $\beta$ generation and the NLRP3 inflammasome activation. Tschopp and colleagues (109) suggest that high level of glucose induces ROS generation, which subsequently activates the NLRP3 inflammasome by mediating the direct binding of NLRP3 and thioredoxin-interacting protein (TXNIP) in $\beta$-cells. However, O'Neill and colleagues (110) reported that neither glucose nor TXNIP mediates the NLRP3 inflammasome activation and IL-1 $\beta$ processing. Instead, they found that IAPP induced the NLRP3 inflammasome activation and IL-1 $\beta$ maturation. IAPP is a hormone secreted together with insulin and deposited in the islet interstitium in the patients with T2DM. It is known that IAPP exhibits a cytotoxic effect on $\beta$-cells and induces cell dysfunction and apoptosis (149). Therefore, these studies provide a mechanistic insight into the link of the NLRP3 inflammasome and T2DM.

A recent study also indicates a central role for the NLRP3 inflammasome in atherosclerosis (34). Atherosclerosis is a chronic inflammatory disease characteristic of the accumulation of lipid components and the recruitment of immune cells in atherosclerotic lesions (143). Despite the intensive investigation of the involvement of immune cell types such as macrophages, DCs, lymphocytes, and natural killer (NK) cells in the development of atherosclerotic plaque, agents that promote inflammation and recruit other immune cells in an early phase of atherosclerosis remain largely undescribed. Duewell et al. (느) observed a deposition of minute cholesterol crystals in early diet-induced atherosclerotic lesions, which was associated with macrophage recruitment. Cholesterol crystals generated in vitro induced NLRP3/ASC inflammasome activation and caspase-1/IL-1 $\beta /$ IL-18 cleavage in LPS-primed human peripheral blood mononuclear cells and mouse macrophages. Mechanistically, cholesterol crystal-induced NLRP3 inflammasome activation was sensitive to cytochalasin $\mathrm{D}$ and bafilomycin treatment, suggesting the requirement of phagocytosis and lysosome acidification in this process ( $\underline{34})$. This is consistent with the common theme that NLRP3 inflammasome activation can be induced by crystals such as MSU, silica, or asbestos ( $\underline{30}$, $\underline{44}, \underline{42})$. Furthermore, in vivo experiments using bone marrow chimera suggest a critical role for myeloid cell-derived NLRP3, ASC, and IL-1 $\beta / \beta$ in the development of atherosclerotic lesions. Because ROS also promotes the development of atherosclerosis (150), it will be of interest to test the involvement of ROS in cholesterol crystal-induced NLRP3 inflammasome activation. 


\section{The NLRP3 Inflammasome in Intestinal Inflammation and Tumorigenesis}

Colorectal cancer is a leading contributor to cancer-related deaths in the United States and is a major complication of inflammatory bowel diseases such as ulcerative colitis and Crohn's disease (151). Inflammatory bowel disease and colorectal cancer are commonly associated with the exaggerated production of inflammatory cytokines. Inflammatory cytokines such as IL-1 $/ / \beta$, IL-6, and TNF- $\alpha$ play an essential role in inflammation-promoted tumorigenesis (152). Based on the key role of the caspase-1 inflammasome in IL-1 $1 \beta$ processing, we and others studied the role of the NLRP3 inflammasome in colitis and colitis-associated cancer (CAC).

Using dextran sulfate sodium (DSS)-induced colitis and DSS+azoxymethane-induced CAC animal models, several groups unexpectedly found that a protective role is played by components of the inflammasome in controlling intestinal homeostasis and preventing tumorigenesis (153-155). Mice deficient in NLRP3, ASC, or caspase-1 were more susceptible to colitis and CAC. This phenotype was associated with decreased secretion of IL-1 $\beta$ and IL-18 locally and systemically. Our data suggest that NLRP3 derived from the hematopoietic compartment, rather than from intestinal epithelial cells or stromal cells, is responsible for protection against increased intestinal inflammation and tumorigenesis. Similarly, ASC and caspase-1 are also protective against inflammation-driven intestinal tumorigenesis (153). Kanneganti and colleagues (154) focused on the DSS-induced acute colitis model and showed that NLRP3 signaling is critical for protection against DSSinduced colitis but that NLRP3 signaling in nonhematopoietic cells is more important for protection against DSS-induced colitis than NLRP3 expression in the hematopoietic compartment. Furthermore, Saleh and colleagues (155) observed a similar protective role played by caspase-1 against DSS-induced colitis. Casp1 $1^{-/}$mice exhibited enhanced intestinal inflammation and NF- $\mathrm{kB}$ activation and impaired tissue repair after DSS treatment (155). Because IL- $1 \beta$ induces the activation of NF- $\kappa B$ and MAPK pathways by binding to the IL-1 receptor and promoting the production of other proinflammatory cytokines (156), it is unlikely that IL- $1 \beta$ is responsible for the NLRP3-mediated protective function in colitis and CAC animal models, although the usage of IL- $1 \beta$-deficient mice is required to test the hypothesis. Instead, IL-18 is required for intestinal homeostasis and inflammation. Using $I l 18^{-/-}$and $I l 18 r 1^{-/-}$mice, Trinchieri and colleagues (157) found that IL-18 signaling protects against tissue damage in DSS-induced colitis and DSS+azoxymethane-induced

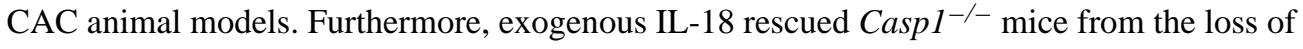
body weight in colitis-induced colitis (154). Therefore, IL-18 seems to be responsible for NLRP3 inflammasome-mediated protective role against intestinal inflammation, tissue damage, and tumorigenesis.

In addition to the inflammation-driven CAC tumor model, mice injected with EL4 or EG7 thymoma cells have also been used to investigate the role of the NLRP3 inflammasome in tumorigenesis; thus injecting mice induces a cytotoxic T lymphocyte (CTL)-mediated antitumor response (1458). The study reported that the NLRP3 inflammasome is required for a chemotherapy-mediated antitumor response. Mechanistically, the NLRP3 inflammasome is activated by ATP released from chemotherapy-induced dying tumor cells and further activates IFN- $\gamma$-producing CTLs through IL- $1 \beta$ secretion. Given that the 
concentration of exogenous ATP used to activate the NLRP3 inflammasome is much higher than that of ATP released from chemotherapy-induced dying tumor cells (mM versus $\mu \mathrm{M}$ ), other endogenous NLRP3 activators, such as uric acid, may be released during chemotherapy to activate the NLRP3 inflammasome activation in vivo.

\section{The NLRP3 Inflammasome and Liver Injury}

Although the NLRP3 inflammasome plays a protective role in tissue damage during DSSinduced colitis, study of the acetaminophen (APAP)-induced liver injury animal model indicates that the NLRP3 inflammasome amplifies the immune response and exacerbates liver damage (159). APAP treatment induces hepatotoxicity through a toxic metabolic intermediate product, leading to hepatocyte cell death. In response to the initial hepatocytic cell death, the activation of an innate immune response, including inflammatory cytokine production and the recruitment and activation of immune cells such as macrophages, neutrophils, and NK cells, results in sustained sterile inflammation and liver dysfunction. A recent study identified TLR9 and the NLRP3 inflammasome as key mediators in APAPinduced liver injury and inflammation. TLR9 detects endogenous DNA released after APAP-induced liver cell death and upregulates the production of pro-IL-1 $\beta$ and pro-IL-18, which are further cleaved by the NLRP3 inflammasome. Therefore, TLR9 and the NLRP3 inflammasome play nonredundant roles during APAP-induced liver injury and inflammation. However, the stimulus that activates the NLRP3 inflammasome in this model has not been fully investigated. Based on acute and intensive cell death induced by APAP treatment, uric acid, ATP, mitochondria, and/or hyaluronan that are released from dead cells may activate the NLRP3 inflammasome in TLR9-activated macrophages. Furthermore, AIM2 has recently been identified as a cytosolic DNA sensor that mediates caspase-1 activation and IL-1//IL-18 processing $(102,103)$. Further studies are warranted to test the role of AIM2 in liver injury and other disease models that involve extensive cell death such as sepsis.

\section{The NLRP3 Inflammasome and Adaptive Immune Responses}

Besides the proinflammatory role of the NLRP3 inflammasome in innate immune responses, recent studies strongly suggest that NLRP3 inflammasome-mediated cytokines such as IL-1 $\beta$ and IL-18 play an essential role in shaping adaptive immune responses. Several immunogenic $\mathrm{T}$ cell-mediated disease models have been employed to investigate the role of the NLRP3 inflammasome, including experimental autoimmune encephalomyelitis (EAE), arthritis, and CTL-mediated antitumor responses.

IL-1 signaling reportedly regulates early Th17 cell differentiation and plays an essential role for EAE induction (160). Mechanistically, IL-1 signaling induces the expression of IRF4 and ROR $\gamma$ t, two essential transcription factors involved in Th17 differentiation. IL- $1 \beta$ has also been shown to cooperate with IL-23 by inducing the development of IL-17-producing $\gamma \delta$ T cells and thereby promoting EAE development (161). More importantly, the differentiation of human Th17 cells requires the presence of $\operatorname{IL}-1 \beta(162,163)$. Therefore, IL-1 $\beta$ promotes Th17 cell differentiation in both humans and mice. Although IL-1 $\beta$ and IL-18 activate similar signaling pathways such as NF- $\mathrm{KB}$, JNK, and p38 MAPK by recruiting similar intracellular adaptor molecules (MyD88, IRAK, and TRAF6), clear 
differences exist between IL-1 $\beta$ and IL-18 in mediating T cell differentiation. In contrast to IL-1 $\beta$, the role of IL-18 signaling in Th cell differentiation depends on other cooperative cytokines. For example, the synergy of IL-18 with IL-12 induces IFN- $\gamma$-producing Th1 cells (164), whereas IL-18 in combination with IL-2 enhances the production of IL-13, a Th2 cytokine. Finally, by cooperating with IL-23, IL-18 amplifies IL-17 production from polarized Th17 cells. Thus, compared with IL-1 $\beta$, IL-18 exhibits more flexible functions in shaping adaptive $\mathrm{T}$ cell responses, which may explain the distinct functions between IL-1 $\beta$ and IL-18 in some disease models such as intestinal inflammation and T2DM.

Based on the role of IL-1 $\beta$ and IL-18 in T cell differentiation and autoimmune diseases, several groups investigated the role of the inflammasome in T cell-mediated disease models. Our data indicate a strong role for NLRP3 in exacerbating EAE development. This is attributed to the requirement of NLRP3 in antigen-presenting macrophages and DCs to optimally activate naive T cells to form Th1 and Th17 effector cells. Surprisingly, only differences in IL-18 but not in IL-1 $\beta$ were detected in the absence of NLRP3. Verification of an important role for IL-18 was provided by a study of $I l 18^{-/-}$mice, which exhibited a protective phenotype against EAE similar to that of $\mathrm{Nlrp3^{-/ }}$ mice, accompanied by reduced IFN- $\gamma$ and IL-17 (165). Another study also reported that ASC and caspase-1 are required for EAE development by mediating Th1 and Th17 responses; however, they did not find a role for NLRP3 (166). In another study, ASC exacerbated antigen-induced arthritis in an inflammasome-independent and T cell-intrinsic role $(167,168)$. However, the mechanism of ASC-mediated intrinsic T cell activation was not shown. The reason for this discrepancy is not clear but is probably due to different animal models.

Early work has shown that NLRP3 and ASC mediate contact hypersensitivity, which is composed of $\mathrm{T}$ cell-mediated cellular immune responses to contact allergens (132). As mentioned above, more recent work using mice bearing mutant Nlrp3 gene variants equivalent to those found in MWS showed that the mice exhibited a skin inflammation that is characterized by a dominant Th17 response (24). Also mentioned above, in a CTLmediated antitumor response, the NLRP3 inflammasome in DCs is essential for CTL induction and tumor killing during chemotherapy, which is dependent on IL-1 $\beta$-mediated IFN $-\gamma$ production (158). In summary, the NLRP3 inflammasome mediates the production of IL-1 $\beta$ and IL-18, which cooperate with other inflammatory cytokines to regulate the generation of $\mathrm{T}$ effector cells and influence disease progression. These studies expand the role of the inflammasome to the regulation of adaptive immunity.

\section{The NLR and Signaling Pathways Other than the Inflammasome}

Although the focus of this review is on NLRs that regulate inflammasome activation, it is notable that there are other NLR-regulated pathways. As our group has reviewed these other NLRs in a recent review (169), these findings are only briefly summarized here. Key pathways that are controlled by NLRs are NF- $\kappa B$ /MAP kinase activation and type I IFN (IFN- $\alpha / \beta$ ) induction. The NOD1 and NOD2 proteins were the first NLRs found to regulate $\mathrm{NF}-\kappa \mathrm{B}$ and MAPK and have been extensively reviewed elsewhere. Our own studies suggest that NLRP12 (also known as Monarch-1 or Pypaf7) suppresses the activation of the noncanonical NF-\$B pathway by reducing the level of NIK via a proteasome-dependent 
pathway by using both overexpression and siRNA approaches (170). Another NLR, NLRC5, has been recently characterized as a negative regulator in both NF- $\kappa \mathrm{B}$ and type I IFN signaling pathways (171). NLRC5 contains an N-terminal CARD-like domain, and is widely expressed in various tissues and cell types in both human and mouse. Cui et al. (171) showed that NLRC5 negatively regulates canonical NF- $\kappa \mathrm{B}$ activation and directly interacts with IKKa and IKK $\beta$ to inhibit their phosphorylation. However, NF- $\kappa \mathrm{B}$ activation was not affected by NLRC5 in two other studies $(172,173)$. Considering the limitation of overexpression and siRNA approaches, generation of $\mathrm{Nlrc5} 5^{-/-}$mice is required to fully understand the function of NLRC5 in the immune system. Several recent reports have also identified the intersection of NLRs with IFN- $\alpha / \beta$ production. The first NLR found to play such a role is NLRX1 (174). NLRX1 is specifically located at the mitochondria by a mitochondrial-targeting sequence at its N-terminus. It interacts with the mitochondrial antiviral signaling protein (MAVS; also known as IPS-1, VISA, and Cardif), which serves as an immune-activating adaptor for type I IFN production. MAVS activates the transcription factors IRF3 and NF- $\kappa \mathrm{B}$ signaling pathways, leading to the production of IFN$\alpha / \beta$ and proinflammatory cytokines such as IL-6. During viral infection, MAVS interacts with members of the RLR family, which are RNA helicases that can interact with viral RNA to cause IRF3 and NF- $\kappa \mathrm{B}$ activation, leading to Ifn $\alpha \beta$ gene transcription. MAVS-RIG-I interaction is impeded by NLRX1, thus the latter serves as a negative regulator of IFN- $\alpha / \beta$ induction. In contrast, NOD2 uses MAVS to activate an anti-viral IRF3 response, leading to enhanced IFN- $\alpha / \beta$ induction (175). Finally, one report has shown that NLRC5 can inhibit RIG-I/MDA5-mediated type I IFN production by directly interacting with the two molecules, but not with MAVS (171). However, two other studies reported different functions of NLRC5 in the immune system $(172,173)$ and found that NLRC5 positively mediates the generation of type I IFN and anti-viral target genes. The biologic relevance of these less-studied NLRs in IFN- $\alpha / \beta$ remains to be validated in physiologically relevant systems.

\section{CONCLUDING REMARKS}

A key function of a subgroup of NLR proteins is to mediate inflammasome function. NLRmediated inflammasome activation is important in host response not only to bacteria, fungi, viruses, and possibly parasites, but also to DAMPs (Figure 4). In addition, the roles of these NLRs have been extended to metabolic disorders, tumorigenesis, and autoimmune disorders. Despite this wealth of information, the exact mode by which the NLR inflammasome is activated is still unclear and awaits the identification of other mediators and interacting partners to fully elucidate the mechanism of its action.

\section{Acknowledgments}

The authors apologize to those whose citations were omitted owing to space limitations. J. Ting is supported by NIH grants R01-DE016326, U54-AI057157, R01-AI063031, and R01-DE018281. B. Davis is supported by NIH R21 CA131645 and the Crohn's and Colitis Foundation of America. H. Wen is supported by the American Heart Association Mid-Atlantic Affiliate and the Cancer Research Institute Postdoctoral Fellowship. 


\section{LITERATURE CITED}

1. Ting JP, Lovering RC, Alnemri ES, Bertin J, Boss JM, Davis BK, et al. The NLR gene family: a standard nomenclature. Immunity. 2008; 28:285--87. [PubMed: 18341998]

2. Ting JP, Davis BK. CATERPILLER: a novel gene family important in immunity, cell death, and diseases. Annu. Rev. Immunol. 2005; 23:387--414. [PubMed: 15771576]

3. Ausubel FM. Are innate immune signaling pathways in plants and animals conserved? Nat. Immunol. 2005; 6:973--79. [PubMed: 16177805]

4. Rast JP, Smith LC, Loza-Coll M, Hibino T, Litman GW. Genomic insights into the immune system of the sea urchin. Science. 2006; 314:952--56. [PubMed: 17095692]

5. Schroder K, Tschopp J. The inflammasomes. Cell. 2010; 140:821--32. [PubMed: 20303873]

6. Martinon F, Burns K, Tschopp J. The inflammasome: a molecular platform triggering activation of inflammatory caspases and processing of proIL- $\beta$. Mol. Cell. 2002; 10:417--26. [PubMed: 12191486]

7. Keller M, Ruegg A, Werner S, Beer HD. Active caspase-1 is a regulator of unconventional protein secretion. Cell. 2008; 132:818--31. [PubMed: 18329368]

8. Faustin B, Lartigue L, Bruey JM, Luciano F, Sergienko E, Bailly-Maitre B, et al. Reconstituted NALP1 inflammasome reveals two-step mechanism of caspase-1 activation. Mol. Cell. 2007; 25:713--24. [PubMed: 17349957]

9. Agostini L, Martinon F, Burns K, McDermott MF, Hawkins PN, Tschopp J. NALP3 forms an IL-1 $\beta$-processing inflammasome with increased activity in Muckle-Wells autoinflammatory disorder. Immunity. 2004; 20:319--25. [PubMed: 15030775]

10. Grenier JM, Wang L, Manji GA, Huang WJ, Al-Garawi A, et al. Functional screening of five PYPAF family members identifies PYPAF5 as a novel regulator of NF- $\kappa \mathrm{B}$ and caspase-1. FEBS Lett. 2002; 530:73--78. [PubMed: 12387869]

11. Wang L, Manji GA, Grenier JM, Al-Garawi A, Merriam S, et al. PYPAF7, a novel PYRINcontaining Apaf1-like protein that regulates activation of NF- $\kappa \mathrm{B}$ and caspase-1-dependent cytokine processing. J. Biol. Chem. 2002; 277:29874--80. [PubMed: 12019269]

12. Poyet JL, Srinivasula SM, Tnani M, Razmara M, Fernandes-Alnemri T, Alnemri ES. Identification of Ipaf, a human caspase-1-activating protein related to Apaf-1. J. Biol. Chem. 2001; 276:28309--13. [PubMed: 11390368]

13. O'Connor W Jr, Harton JA, Zhu X, Linhoff MW, Ting JP. Cutting edge: CIAS1/cryopyrin/ PYPAF1/NALP3/CATERPILLER 1.1 is an inducible inflammatory mediator with NF- $\kappa$ B suppressive properties. J. Immunol. 2003; 171:6329--33. [PubMed: 14662828]

14. Hoffman HM, Mueller JL, Broide DH, Wanderer AA, Kolodner RD. Mutation of a new gene encoding a putative pyrin-like protein causes familial cold autoinflammatory syndrome and Muckle-Wells syndrome. Nat. Genet. 2001; 29:301--5. [PubMed: 11687797]

15. Allen IC, Scull MA, Moore CB, Holl EK, McElvania-TeKippe E, et al. The NLRP3 inflammasome mediates in vivo innate immunity to influenza A virus through recognition of viral RNA. Immunity. 2009; 30:556--65. [PubMed: 19362020]

16. Mayor A, Martinon F, De Smedt T, Petrilli V, Tschopp J. A crucial function of SGT1 and HSP90 in inflammasome activity links mammalian and plant innate immune responses. Nat. Immunol. 2007; 8:497--503. [PubMed: 17435760]

17. Hahn JS. Regulation of Nod1 by Hsp90 chaperone complex. FEBS Lett. 2005; 579:4513--19. [PubMed: 16083881]

18. Arthur JC, Lich JD, Aziz RK, Kotb M, Ting JP. Heat shock protein 90 associates with monarch-1 and regulates its ability to promote degradation of NF- $\kappa \mathrm{B}$-inducing kinase. J. Immunol. 2007; 179:6291--96. [PubMed: 17947705]

19. Hoffman HM, Wanderer AA. Inflammasome and IL-1b mediated disorders. Curr. Allergy Asthma Rep. 2010; 10:229-35. [PubMed: 20425006]

20. Masters SL, Simon A, Aksentijevich I, Kastner DL. Horror autoinflammaticus: the molecular pathophysiology of autoinflammatory disease. Annu. Rev. Immunol. 2009; 27:621--68. [PubMed: 19302049] 
21. Duncan JA, Bergstralh DT, Wang Y, Willingham SB, Ye Z, et al. Cryopyrin/NALP3 binds ATP/ dATP, is an ATPase, and requires ATP binding to mediate inflammatory signaling. Proc. Natl. Acad. Sci. USA. 2007; 104:8041--46. [PubMed: 17483456]

22. Willingham SB, Bergstralh DT, O'Connor W, Morrison AC, Taxman DJ, et al. Microbial pathogen-induced necrotic cell death mediated by the inflammasome components CIAS1/ cryopyrin/NLRP3 and ASC. Cell Host Microbe. 2007; 2:147--59. [PubMed: 18005730]

23. Saito M, Nishikomori R, Kambe N, Fujisawa A, Tanizaki H, et al. Disease-associated CIAS1 mutations induce monocyte death, revealing low-level mosaicism in mutation-negative cryopyrinassociated periodic syndrome patients. Blood. 2008; 111:2132--41. [PubMed: 18063752]

24. Meng G, Zhang F, Fuss I, Kitani A, Strober W. A mutation in the Nlrp3 gene causing inflammasome hyperactivation potentiates Th17 cell-dominant immune responses. Immunity. 2009; 30:860--74. [PubMed: 19501001]

25. Brydges SD, Mueller JL, McGeough MD, Pena CA, Misaghi A, et al. Inflammasome-mediated disease animal models reveal roles for innate but not adaptive immunity. Immunity. 2009; 30:875--87. [PubMed: 19501000]

26. Rock KL, Latz E, Ontiveros F, Kono H. The sterile inflammatory response. Annu. Rev. Immunol. 2010; 28:321--42. [PubMed: 20307211]

27. Iyer SS, Pulskens WP, Sadler JJ, Butter LM, Teske GJ, et al. Necrotic cells trigger a sterile inflammatory response through the Nlrp3 inflammasome. Proc. Natl. Acad. Sci. USA. 2009; 106:20388--93. [PubMed: 19918053]

28. Mariathasan S, Weiss DS, Newton K, McBride J, O'Rourke K, et al. Cryopyrin activates the inflammasome in response to toxins and ATP. Nature. 2006; 440:228--32. [PubMed: 16407890]

29. Ferrari D, Chiozzi P, Falzoni S, Dal Susino M, Melchiorri L, et al. Extracellular ATP triggers IL-1 $\beta$ release by activating the purinergic P2Z receptor of human macrophages. J. Immunol. 1997; 159:1451--58. [PubMed: 9233643]

30. Martinon F, Petrilli V, Mayor A, Tardivel A, Tschopp J. Gout-associated uric acid crystals activate the NALP3 inflammasome. Nature. 2006; 440:237--41. [PubMed: 16407889]

31. Martinon F. Update on biology: uric acid and the activation of immune and inflammatory cells. Curr. Rheumatol. Rep. 2010; 12:135--41. [PubMed: 20425023]

32. So A, De Smedt T, Revaz S, Tschopp J. A pilot study of IL-1 inhibition by anakinra in acute gout. Arthritis Res. Ther. 2007; 9:R28. [PubMed: 17352828]

33. Halle A, Hornung V, Petzold GC, Stewart CR, Monks BG, et al. The NALP3 inflammasome is involved in the innate immune response to amyloid- $\beta$. Nat. Immunol. 2008; 9:857--65. [PubMed: 18604209]

34. Duewell P, Kono H, Rayner KJ, Sirois CM, Vladimer G, et al. NLRP3 inflammasomes are required for atherogenesis and activated by cholesterol crystals. Nature. 2010; 464:1357--61. [PubMed: 20428172]

35. Yamasaki K, Muto J, Taylor KR, Cogen AL, Audish D, et al. NLRP3/cryopyrin is necessary for interleukin-1 $\beta$ (IL-1 $\beta$ ) release in response to hyaluronan, an endogenous trigger of inflammation in response to injury. J. Biol. Chem. 284:12762--71. 2009

36. Rock KL, Kono H. The inflammatory response to cell death. Annu. Rev. Pathol. 2008; 3:99--126. [PubMed: 18039143]

37. Riteau N, Gasse P, Fauconnier L, Gombault A, Couegnat M, et al. Extracellular ATP is a danger signal activating $\mathrm{P}_{2} \mathrm{X}_{7}$ receptor in lung inflammation and fibrosis. Am. J. Respir. Crit. Care Med. 2010; 182:774--83. [PubMed: 20522787]

38. Muller T, Paula Vieira R, Grimm M, Durk T, Cicko S, et al. A potential role for P2X7R in allergic airway inflammation in mice and humans. Am. J. Respir. Cell Mol. Biol. 2010 In press.

39. Nakae S, Komiyama Y, Yokoyama H, Nambu A, Umeda M, et al. IL-1 is required for allergenspecific Th2 cell activation and the development of airway hypersensitivity response. Int. Immunol. 2003; 15:483--90. [PubMed: 12663678]

40. Gasse P, Riteau N, Charron S, Girre S, Fick L, et al. Uric acid is a danger signal activating NALP3 inflammasome in lung injury inflammation and fibrosis. Am. J. Respir. Crit. Care Med. 2009; 179:903--13. [PubMed: 19218193] 
41. Idzko M, Hammad H, van Nimwegen M, Kool M, Willart MA, et al. Extracellular ATP triggers and maintains asthmatic airway inflammation by activating dendritic cells. Nat. Med. 2007; 13:913--19. [PubMed: 17632526]

42. Dostert C, Petrilli V, Van Bruggen R, Steele C, Mossman BT, Tschopp J. Innate immune activation through Nalp3 inflammasome sensing of asbestos and silica. Science. 2008; 320:674--77. [PubMed: 18403674]

43. Cassel SL, Eisenbarth SC, Iyer SS, Sadler JJ, Colegio OR, et al. The Nalp3 inflammasome is essential for the development of silicosis. Proc. Natl. Acad. Sci. USA. 2008; 105:9035--40. [PubMed: 18577586]

44. Hornung V, Bauernfeind F, Halle A, Samstad EO, Kono H, et al. Silica crystals and aluminum salts activate the NALP3 inflammasome through phagosomal destabilization. Nat. Immunol. 2008; 9:847--56. [PubMed: 18604214]

45. Caicedo MS, Desai R, McAllister K, Reddy A, Jacobs JJ, Hallab NJ. Soluble and particulate CoCr-Mo alloy implant metals activate the inflammasome danger signaling pathway in human macrophages: a novel mechanism for implant debris reactivity. J. Orthop. Res. 2009; 27:847--54. [PubMed: 19105226]

46. Maitra R, Clement CC, Scharf B, Crisi GM, Chitta S, et al. Endosomal damage and TLR2 mediated inflammasome activation by alkane particles in the generation of aseptic osteolysis. Mol. Immunol. 2009; 47:175--84. [PubMed: 19804908]

47. Eisenbarth SC, Colegio OR, O'Connor W, Sutterwala FS, Flavell RA. Crucial role for the Nalp3 inflammasome in the immunostimulatory properties of aluminium adjuvants. Nature. 2008; 453:1122--26. [PubMed: 18496530]

48. Li H, Willingham SB, Ting JP, Re F. Cutting edge: inflammasome activation by alum and alum's adjuvant effect are mediated by NLRP3. J. Immunol. 2008; 181:17--21. [PubMed: 18566365]

49. Franchi L, Nunez G. The Nlrp3 inflammasome is critical for aluminium hydroxide-mediated IL-1 $\beta$ secretion but dispensable for adjuvant activity. Eur. J. Immunol. 2008; 38:2085--89. [PubMed: 18624356]

50. Kool M, Petrilli V, De Smedt T, Rolaz A, Hammad H, et al. Cutting edge: alum adjuvant stimulates inflammatory dendritic cells through activation of the NALP3 inflammasome. J. Immunol. 2008; 181:3755--59. [PubMed: 18768827]

51. McKee AS, Munks MW, MacLeod MK, Fleenor CJ, Van Rooijen N, et al. Alum induces innate immune responses through macrophage and mast cell sensors, but these sensors are not required for alum to act as an adjuvant for specific immunity. J. Immunol. 2009; 183:4403--14. [PubMed: 19734227]

52. Feldmeyer L, Keller M, Niklaus G, Hohl D, Werner S, Beer HD. The inflammasome mediates UVB-induced activation and secretion of interleukin-1 $\beta$ by keratinocytes. Curr. Biol. 2007; 17:1140--45. [PubMed: 17600714]

53. Watanabe H, Gaide O, Petrilli V, Martinon F, Contassot E, et al. Activation of the IL-1 $\beta$ processing inflammasome is involved in contact hypersensitivity. J. Invest. Dermatol. 2007; 127:1956--63. [PubMed: 17429439]

54. Broz P, Newton K, Lamkanfi M, Mariathasan S, Dixit VM, Monack DM. Redundant roles for inflammasome receptors NLRP3 and NLRC4 in host defense against Salmonella. J. Exp. Med. 2010; 207:1745--55. [PubMed: 20603313]

55. Warren SE, Mao DP, Rodriguez AE, Miao EA, Aderem A. Multiple Nod-like receptors activate caspase 1 during Listeria monocytogenes infection. J. Immunol. 2008; 180:7558--64. [PubMed: 18490757]

56. Craven RR, Gao X, Allen IC, Gris D, Bubeck Wardenburg J, et al. Staphylococcus aureus ahemolysin activates the NLRP3-inflammasome in human and mouse monocytic cells. PLoS ONE. 2009; 4:e7446. [PubMed: 19826485]

57. Munoz-Planillo R, Franchi L, Miller LS, Nunez G. A critical role for hemolysins and bacterial lipoproteins in Staphylococcus aureus-induced activation of the Nlrp3 inflammasome. J. Immunol. 2009; 183:3942--48. [PubMed: 19717510] 
58. Meixenberger K, Pache F, Eitel J, Schmeck B, Hippenstiel S, et al. Listeria monocytogenesinfected human peripheral blood mononuclear cells produce IL-1 $\beta$, depending on listeriolysin O and NLRP3. J. Immunol. 2010; 184:922--30. [PubMed: 20008285]

59. $\mathrm{Ng}$ J, Hirota SA, Gross O, Li Y, Ulke-Lemee A, et al. Clostridium difficile toxin-induced inflammation and intestinal injury are mediated by the inflammasome. Gastroenterology. 2010; 139:542--52. [PubMed: 20398664]

60. Chu J, Thomas LM, Watkins SC, Franchi L, Nunez G, Salter RD. Cholesterol-dependent cytolysins induce rapid release of mature IL- $1 \beta$ from murine macrophages in a NLRP3 inflammasome and cathepsin B-dependent manner. J. Leukoc. Biol. 2009; 86:1227--38. [PubMed: 19675207]

61. Gurcel L, Abrami L, Girardin S, Tschopp J, Van Der Goot FG. Caspase-1 activation of lipid metabolic pathways in response to bacterial pore-forming toxins promotes cell survival. Cell. 2006; 126:1135--45. [PubMed: 16990137]

62. Ichinohe T, Lee HK, Ogura Y, Flavell R, Iwasaki A. Inflammasome recognition of influenza virus is essential for adaptive immune responses. J. Exp. Med. 2009; 206:79--87. [PubMed: 19139171]

63. Thomas PG, Dash P, Aldridge JR Jr, Ellebedy AH, Reynolds C, et al. The intracellular sensor NLRP3 mediates key innate and healing responses to influenza A virus via the regulation of caspase-1. Immunity. 2009; 30:566--75. [PubMed: 19362023]

64. Ichinohe T, Pang IK, Iwasaki A. Influenza virus activates inflammasomes via its intracellular M2 ion channel. Nat. Immunol. 2010; 11:404--10. [PubMed: 20383149]

65. Muruve DA, Petrilli V, Zaiss AK, White LR, Clark SA, et al. The inflammasome recognizes cytosolic microbial and host DNA and triggers an innate immune response. Nature. 2008; 452:103--7. [PubMed: 18288107]

66. Delaloye J, Roger T, Steiner-Tardivel QG, Le Roy D, Knaup Reymond M, et al. Innate immune sensing of modified vaccinia virus Ankara (MVA) is mediated by TLR2-TLR6, MDA-5 and the NALP3 inflammasome. PLoS Pathog. 2009; 5:e1000480. [PubMed: 19543380]

67. Hornung V, Ablasser A, Charrel-Dennis M, Bauernfeind F, Horvath G, et al. AIM2 recognizes cytosolic dsDNA and forms a caspase-1-activating inflammasome with ASC. Nature. 2009; 458:514--18. [PubMed: 19158675]

68. Vonk AG, Netea MG, van Krieken JH, Iwakura Y, Van Der Meer JW, Kullberg BJ. Endogenous interleukin (IL)-1a and IL-1 $\beta$ are crucial for host defense against disseminated candidiasis. J. Infect. Dis. 2006; 193:1419--26. [PubMed: 16619190]

69. Lamkanfi M, Malireddi RK, Kanneganti TD. Fungal zymosan and mannan activate the cryopyrin inflammasome. J. Biol. Chem. 2009; 284:20574--81. [PubMed: 19509280]

70. Said-Sadier N, Padilla E, Langsley G, Ojcius DM. Aspergillus fumigatus stimulates the NLRP3 inflammasome through a pathway requiring ROS production and the Syk tyrosine kinase. PLoS ONE. 2010; 5:e10008. [PubMed: 20368800]

71. Gross O, Poeck H, Bscheider M, Dostert C, Hannesschlager N, et al. Syk kinase signalling couples to the Nlrp3 inflammasome for anti-fungal host defence. Nature. 2009; 459:433--36. [PubMed: 19339971]

72. Hise AG, Tomalka J, Ganesan S, Patel K, Hall BA, et al. An essential role for the NLRP3 inflammasome in host defense against the human fungal pathogen Candida albicans. Cell Host Microbe. 2009; 5:487--97. [PubMed: 19454352]

73. Joly S, Ma N, Sadler JJ, Soll DR, Cassel SL, Sutterwala FS. Cutting edge: Candida albicans hyphae formation triggers activation of the Nlrp3 inflammasome. J. Immunol. 2009; 183:3578--81. [PubMed: 19684085]

74. Shio MT, Eisenbarth SC, Savaria M, Vinet AF, Bellemare MJ, et al. Malarial hemozoin activates the NLRP3 inflammasome through Lyn and Syk kinases. PLoS Pathog. 2009; 5:e1000559. [PubMed: 19696895]

75. Coban C, Igari Y, Yagi M, Reimer T, Koyama S, et al. Immunogenicity of whole-parasite vaccines against Plasmodium falciparum involves malarial hemozoin and host TLR9. Cell Host Microbe. 2010; 7:50--61. [PubMed: 20114028] 
76. Reimer T, Shaw MH, Franchi L, Coban C, Ishii KJ, et al. Experimental cerebral malaria progresses independently of the Nlrp3 inflammasome. Eur. J. Immunol. 2010; 40:764--69. [PubMed: 19950187]

77. Mariathasan S, Newton K, Monack DM, Vucic D, French DM, et al. Differential activation of the inflammasome by caspase-1 adaptors ASC and Ipaf. Nature. 2004; 430:213--18. [PubMed: 15190255]

78. Suzuki T, Franchi L, Toma C, Ashida H, Ogawa M, et al. Differential regulation of caspase-1 activation, pyroptosis, and autophagy via Ipaf and ASC in Shigella-infected macrophages. PLoS Pathog. 2007; 3:e111. [PubMed: 17696608]

79. Cooney R, Baker J, Brain O, Danis B, Pichulik T, et al. NOD2 stimulation induces autophagy in dendritic cells influencing bacterial handling and antigen presentation. Nat. Med. 2010; 16:90--97. [PubMed: 19966812]

80. Travassos LH, Carneiro LA, Ramjeet M, Hussey S, Kim YG, et al. Nod1 and Nod2 direct autophagy by recruiting ATG16L1 to the plasma membrane at the site of bacterial entry. Nat. Immunol. 2010; 11:55--62. [PubMed: 19898471]

81. Sutterwala FS, Mijares LA, Li L, Ogura Y, Kazmierczak BI, Flavell RA. Immune recognition of Pseudomonas aeruginosa mediated by the IPAF/NLRC4 inflammasome. J. Exp. Med. 2007; 204:3235--45. [PubMed: 18070936]

82. Miao EA, Ernst RK, Dors M, Mao DP, Aderem A. Pseudomonas aeruginosa activates caspase 1 through Ipaf. Proc. Natl. Acad. Sci. USA. 2008; 105:2562--67. [PubMed: 18256184]

83. Diez E, Lee SH, Gauthier S, Yaraghi Z, Tremblay M, et al. Bircle is the gene within the Lgn1 locus associated with resistance to Legionella pneumophila. Nat. Genet. 2003; 33:55--60. [PubMed: 12483212]

84. Vinzing M, Eitel J, Lippmann J, Hocke AC, Zahlten J, et al. NAIP and Ipaf control Legionella pneumophila replication in human cells. J. Immunol. 2008; 180:6808--15. [PubMed: 18453601]

85. Ren T, Zamboni DS, Roy CR, Dietrich WF, Vance RE. Flagellin-deficient Legionella mutants evade caspase-1- and Naip5-mediated macrophage immunity. PLoS Pathog. 2006; 2:e18. [PubMed: 16552444]

86. Lightfield KL, Persson J, Brubaker SW, Witte CE, von Moltke J, et al. Critical function for Naip5 in inflammasome activation by a conserved carboxy-terminal domain of flagellin. Nat. Immunol. 2008; 9:1171--78. [PubMed: 18724372]

87. Zamboni DS, Kobayashi KS, Kohlsdorf T, Ogura Y, Long EM, et al. The Bircle cytosolic patternrecognition receptor contributes to the detection and control of Legionella pneumophila infection. Nat. Immunol. 2006; 7:318--25. [PubMed: 16444259]

88. Miao EA, Alpuche-Aranda CM, Dors M, Clark AE, Bader MW, et al. Cytoplasmic flagellin activates caspase- 1 and secretion of interleukin $1 \beta$ via Ipaf. Nat. Immunol. 2006; 7:569--75. [PubMed: 16648853]

89. Franchi L, Amer A, Body-Malapel M, Kanneganti TD, Ozoren N, et al. Cytosolic flagellin requires Ipaf for activation of caspase- 1 and interleukin $1 \beta$ in salmonella-infected macrophages. Nat. Immunol. 2006; 7:576--82. [PubMed: 16648852]

90. Miao EA, Mao DP, Yudkovsky N, Bonneau R, Lorang CG, et al. Innate immune detection of the type III secretion apparatus through the NLRC4 inflammasome. Proc. Natl. Acad. Sci. USA. 2010; 107:3076--80. [PubMed: 20133635]

91. Petrilli V, Papin S, Dostert C, Mayor A, Martinon F, Tschopp J. Activation of the NALP3 inflammasome is triggered by low intracellular potassium concentration. Cell Death Differ. 2007; 14:1583--89. [PubMed: 17599094]

92. Arlehamn CS, Petrilli V, Gross O, Tschopp J, Evans TJ. The role of potassium in inflammasome activation by bacteria. J. Biol. Chem. 285:10508--18. [PubMed: 20097760]

93. Kummer JA, Broekhuizen R, Everett H, Agostini L, Kuijk L, et al. Inflammasome components NALP 1 and 3 show distinct but separate expression profiles in human tissues suggesting a sitespecific role in the inflammatory response. J. Histochem. Cytochem. 2007; 55:443--52. [PubMed: 17164409] 
94. Hlaing T, Guo RF, Dilley KA, Loussia JM, Morrish TA, et al. Molecular cloning and characterization of DEFCAP-L and -S, two isoforms of a novel member of the mammalian Ced-4 family of apoptosis proteins. J. Biol. Chem. 2001; 276:9230--38. [PubMed: 11076957]

95. Boyden ED, Dietrich WF. Nalp1b controls mouse macrophage susceptibility to anthrax lethal toxin. Nat. Genet. 2006; 38:240--44. [PubMed: 16429160]

96. Nour AM, Yeung YG, Santambrogio L, Boyden ED, Stanley ER, Brojatsch J. Anthrax lethal toxin triggers the formation of a membrane-associated inflammasome complex in murine macrophages. Infect. Immun. 2009; 77:1262--71. [PubMed: 19124602]

97. Hanna PC, Acosta D, Collier RJ. On the role of macrophages in anthrax. Proc. Natl. Acad. Sci. USA. 1993; 90:10198--201. [PubMed: 8234277]

98. Terra JK, Cote CK, France B, Jenkins AL, Bozue JA, et al. Cutting edge: resistance to Bacillus anthracis infection mediated by a lethal toxin sensitive allele of Nalp1b/Nlrp1b. J. Immunol. 2010; 184:17--20. [PubMed: 19949100]

99. Liao KC, Mogridge J. Expression of Nlrp1b inflammasome components in human fibroblasts confers susceptibility to anthrax lethal toxin. Infect. Immun. 2009; 77:4455-62. [PubMed: 19651869]

100. DeYoung KL, Ray ME, Su YA, Anzick SL, Johnstone RW, Trapani JA, Meltzer PS, Trent JM. Cloning a novel member of the human interferon-inducible gene family associated with control of tumorigenicity in a model of human melanoma. Oncogene. 1997; 15:453-7. [PubMed: 9242382]

101. Hornung V, Latz E. Intracellular DNA recognition. Nat Rev Immunol. 2010; 10:123-30. [PubMed: 20098460]

102. Fernande-Alnemri T, Yu JW, Juliana C, Solorzano L, Kang S, et al. The AIM2 inflammasome is critical for innate immunity to Francisella tularensis. Nat. Immunol. 2010; 11:385-93. [PubMed: 20351693]

103. Rathinam VA, Jiang Z, Waggoner SN, Sharma S, Cole LE, et al. The AIM2 inflammasome is essential for host defense against cytosolic bacteria and DNA viruses. Nat. Immunol. 2010; 11:395-402. [PubMed: 20351692]

104. Sauer JD, Witte CE, Zemansky J, Hanson B, Lauer P, Portnoy DA. Listeria monocytogenes triggers AIM2-mediated pyroptosis upon infrequent bacteriolysis in the macrophage cytosol. Cell Host Microbe. 2010; 7:412-9. [PubMed: 20417169]

105. Franchi L, Eigenbrod T, Nunez G. Cutting edge: TNF-a mediates sensitization to ATP and silica via the NLRP3 inflammasome in the absence of microbial stimulation. J. Immunol. 2009; 183:792-96. [PubMed: 19542372]

106. Bauernfeind FG, Horvath G, Stutz A, Alnemri ES, MacDonald K, et al. Cutting edge: NF- $\kappa B$ activating pattern recognition and cytokine receptors license NLRP3 inflammasome activation by regulating NLRP3 expression. J. Immunol. 2009; 183:787-91. [PubMed: 19570822]

107. Meissner F, Molawi K, Zychlinsky A. Superoxide dismutase 1 regulates caspase- 1 and endotoxic shock. Nat. Immunol. 2008; 9:866--72. [PubMed: 18604212]

108. Meissner F, Seger RA, Moshous D, Fischer A, Reichenbach J, Zychlinsky A. Inflammasome activation in NADPH oxidase defective mononuclear phagocytes from patients with chronic granulomatous disease. Blood. 2010; 116:1570--73. [PubMed: 20495074]

109. Zhou R, Tardivel A, Thorens B, Choi I, Tschopp J. Thioredoxin-interacting protein links oxidative stress to inflammasome activation. Nat. Immunol. 2010; 11:136-40. [PubMed: 20023662]

110. Masters SL, Dunne A, Subramaanian SL, Hull RL, Tannahill GM, et al. Activation of the NLRP3 inflammasome by islet amyloid polypeptide provides a mechanism for enhanced IL-1 $\beta$ in type 2 diabetes. Nat. Immunol. 2010; 11:897-904. [PubMed: 20835230]

111. Bryan NB, Dorfleutner A, Kramer SJ, Yun C, Rojanasakul Y, Stehlik C. Differential splicing of the apoptosis-associated speck like protein containing a caspase recruitment domain (ASC) regulates inflammasomes. J. Inflamm. 2010; 7:23.

112. Rosenstiel P, Huse K, Till A, Hampe J, Hellmig S, et al. A short isoform of NOD2/CARD15, NOD2-S, is an endogenous inhibitor of NOD2/receptor-interacting protein kinase 2-induced signaling pathways. Proc. Natl. Acad. Sci. USA. 2006; 103:3280--85. [PubMed: 16492792] 
113. Stehlik C, Dorfleutner A. COPs and POPs: modulators of inflammasome activity. J. Immunol. 2007; 179:7993--98. [PubMed: 18056338]

114. Chae JJ, Komarow HD, Cheng J, Wood G, Raben N, et al. Targeted disruption of pyrin, the FMF protein, causes heightened sensitivity to endotoxin and a defect in macrophage apoptosis. Mol. Cell. 2003; 11:591--604. [PubMed: 12667444]

115. Chae JJ, Wood G, Masters SL, Richard K, Park G, et al. The B30.2 domain of pyrin, the familial Mediterranean fever protein, interacts directly with caspase- 1 to modulate IL- $1 \beta$ production. Proc. Natl. Acad. Sci. USA. 2006; 103:9982--87. [PubMed: 16785446]

116. Yu JW, Wu J, Zhang Z, Datta P, Ibrahimi I, et al. Cryopyrin and pyrin activate caspase-1, but not NF- $\kappa B$, via ASC oligomerization. Cell Death Differ. 2006; 13:236--49. [PubMed: 16037825]

117. Yu JW, Fernandes-Alnemri T, Datta P, Wu J, Juliana C, et al. Pyrin activates the ASC pyroptosome in response to engagement by autoinflammatory PSTPIP1 mutants. Mol. Cell. 2007; 28:214--27. [PubMed: 17964261]

118. Young JL, Sukhova GK, Foster D, Kisiel W, Libby P, Schonbeck U. The serpin proteinase inhibitor 9 is an endogenous inhibitor of interleukin 1 $\beta$-converting enzyme (caspase-1) activity in human vascular smooth muscle cells. J. Exp. Med. 2000; 191:1535--44. [PubMed: 10790428]

119. Bruey JM, Bruey-Sedano N, Luciano F, Zhai D, Balpai R, et al. Bcl-2 and Bcl-XL regulate proinflammatory caspase-1 activation by interaction with NALP1. Cell. 2007; 129:45--56. [PubMed: 17418785]

120. Guarda G, Dostert C, Staehli F, Cabalzar K, Castillo R, et al. T cells dampen innate immune responses through inhibition of NLRP1 and NLRP3 inflammasomes. Nature. 2009; 460:269--73. [PubMed: 19494813]

121. Taxman DJ, Huang MT, Ting JP. Inflammasome inhibition as a pathogenic stealth mechanism. Cell Host Microbe. 2010; 8:7--11. [PubMed: 20638636]

122. Ray CA, Black RA, Kronheim SR, Greenstreet TA, Sleath PR, et al. Viral inhibition of inflammation: cowpox virus encodes an inhibitor of the interleukin- $1 \beta$ converting enzyme. Cell. 1992; 69:597--604. [PubMed: 1339309]

123. Dobo J, Swanson R, Salvesen GS, Olson ST, Gettins PG. Cytokine response modifier A inhibition of initiator caspases results in covalent complex formation and dissociation of the caspase tetramer. J. Biol. Chem. 2006; 281:38781--90. [PubMed: 17052983]

124. Kettle S, Alcami A, Khanna A, Ehret R, Jassoy C, Smith GL. Vaccinia virus serpin B13R (SPI-2) inhibits interleukin-1 $\beta$-converting enzyme and protects virus-infected cells from TNF- and Fasmediated apoptosis, but does not prevent IL-1 $\beta$-induced fever. J. Gen. Virol. 1997; 78(Pt. 3): 677--85. [PubMed: 9049422]

125. Johnston JB, Barrett JW, Nazarian SH, Goodwin M, Ricciuto D, et al. A poxvirus-encoded pyrin domain protein interacts with ASC-1 to inhibit host inflammatory and apoptotic responses to infection. Immunity. 2005; 23:587--98. [PubMed: 16356857]

126. Rahman MM, Mohamed MR, Kim M, Smallwood S, McFadden G. Co-regulation of NF- $\kappa$ B and inflammasome-mediated inflammatory responses by myxoma virus pyrin domain-containing protein M013. PLoS Pathog. 2009; 5:e1000635. [PubMed: 19851467]

127. Dorfleutner A, Bryan NB, Talbott SJ, Funya KN, Rellick SL, et al. Cellular pyrin domain-only protein 2 is a candidate regulator of inflammasome activation. Infect. Immun. 2007; 75:1484--92. [PubMed: 17178784]

128. Stasakova J, Ferko B, Kittel C, Sereinig S, Romanova J, et al. Influenza A mutant viruses with altered NS1 protein function provoke caspase-1 activation in primary human macrophages, resulting in fast apoptosis and release of high levels of interleukins $1 \beta$ and 18. J. Gen. Virol. 2005; 86:185--95. [PubMed: 15604446]

129. Bump NJ, Hackett M, Hugunin M, Seshagiri S, Brady K, et al. Inhibition of ICE family proteases by baculovirus antiapoptotic protein p35. Science. 1995; 269:1885--88. [PubMed: 7569933]

130. Brodsky IE, Palm NW, Sadanand S, Ryndak MB, Sutterwala FS, et al. A Yersinia effector protein promotes virulence by preventing inflammasome recognition of the type III secretion system. Cell Host Microbe. 2010; 7:376--87. [PubMed: 20478539] 
131. Schotte P, Denecker G, Van Den Broeke A, Vandenabeele P, Cornelis GR, Beyaert R. Targeting Rac1 by the Yersinia effector protein YopE inhibits caspase-1-mediated maturation and release of interleukin-1 $\beta$. J. Biol. Chem. 2004; 279:25134--42. [PubMed: 15060067]

132. Sutterwala FS, Ogura Y, Szczepanik M, Lara-Tejero M, Lichtenberger GS, et al. Critical role for NALP3/CIAS1/Cryopyrin in innate and adaptive immunity through its regulation of caspase-1. Immunity. 2006; 24:317--27. [PubMed: 16546100]

133. Mayer-Barber KD, Barber DL, Shenderov K, White SD, Wilson MS, et al. Caspase-1 independent IL- $1 \beta$ production is critical for host resistance to Mycobacterium tuberculosis and does not require TLR signaling in vivo. J. Immunol. 2010; 184:3326--30. [PubMed: 20200276]

134. Mishra BB, Moura-Alves P, Sonawane A, Hacohen N, Griffiths G, et al. Mycobacterium tuberculosis protein ESAT-6 is a potent activator of the NLRP3/ASC inflammasome. Cell Microbiol. 2010; 12:1046--63. [PubMed: 20148899]

135. Master SS, Rampini SK, Davis AS, Keller C, Ehlers S, et al. Mycobacterium tuberculosis prevents inflammasome activation. Cell Host Microbe. 2008; 3:224-32. [PubMed: 18407066]

136. Hunag MT, Mortenssen BL, Taxman DJ, Craven RR, Taft-Benz S, et al. Deletion of ripA alleviates suppression of the inflammasome and MAPK by Francisella tularensis. J. Immunol. 185:5476-85.

137. Ulland TK, Buchan BW, Ketterer MR, Fernandes-Alnemri T, Meyerholz DK, et al. Cutting edge: mutation of Francisella tularensis mviN leads to increased macrophage absent in melanoma 2 inflammasome activation and loss of virulence. J. Immunol. 185:2670-74. [PubMed: 20679532]

138. Littmann M, Albiger B, Frentzen A, Normark S, Henriques-Normark B, Plant L. Streptococcus pneumoniae evades human dendritic cell surveillance by pneumolysin expression. EMBO Mol. Med. 2009; 1:211--22. [PubMed: 20049723]

139. World Health Organization. The World Health Report 2002: Reducing Risks, Promoting Healthy Life. WHO; Geneva: 2002.

140. Zimmet P, Alberti KG, Shaw J. Global and societal implications of the diabetes epidemic. Nature. 2001; 414:782--87. [PubMed: 11742409]

141. Hotamisligil GS. Inflammation and metabolic disorders. Nature. 2006; 444:860--67. [PubMed: 17167474]

142. Feve B, Bastard JP. The role of interleukins in insulin resistance and type 2 diabetes mellitus. Nat. Rev. Endocrinol. 2009; 5:305--11. [PubMed: 19399017]

143. Hansson GK. Inflammation, atherosclerosis, and coronary artery disease. N. Engl. J. Med. 2005; 352:1685--95. [PubMed: 15843671]

144. Lagathu C, Yvan-Charvet L, Bastard JP, Maachi M, Quignard-Boulange A, et al. Long-term treatment with interleukin-1 $\beta$ induces insulin resistance in murine and human adipocytes. Diabetologia. 2006; 49:2162--73. [PubMed: 16865359]

145. Mandrup-Poulsen T, Pickersgill L, Donath MY. Blockade of interleukin 1 in type 1 diabetes mellitus. Nat. Rev. Endocrinol. 2010; 6:158--66. [PubMed: 20173777]

146. Kirii H, Niwa T, Yamada Y, Wada H, Saito K, et al. Lack of interleukin-1 $\beta$ decreases the severity of atherosclerosis in ApoE-deficient mice. Arterioscler. Thromb. Vasc. Biol. 2003; 23:656--60.

147. Larsen CM, Faulenbach M, Vaag A, Volund A, Ehses JA, et al. Interleukin-1-receptor antagonist in type 2 diabetes mellitus. N. Engl. J. Med. 2007; 356:1517-26. [PubMed: 17429083]

148. Lamkanfi M, Mueller JL, Vitari AC, Misaghi S, Fedorova A, et al. Glyburide inhibits Cryopyrin/ Nalp3 inflammasome. J. Cell Biol. 2009; 187:61-70. [PubMed: 19805629]

149. Smith PE, Brender JR, Ramamoorthy A. Induction of negative curvature as a mechanism of cell toxicity by amyloidogenic peptides: the case of islet amyloid polypeptide. J Am Chem Soc. 2009; 131:4470-8. [PubMed: 19278224]

150. Galkina E, Ley K. Immune and inflammatory mechanisms of atherosclerosis. Annu. Rev. Immunol. 2009; 27:165--97. [PubMed: 19302038]

151. Clevers H. At the crossroads of inflammation and cancer. Cell. 2004; 118:671--74. [PubMed: 15369667]

152. Karin M, Greten FR. NF- $\kappa$ B: linking inflammation and immunity to cancer development and progression. Nat. Rev. Immunol. 2005; 5:749--59. [PubMed: 16175180] 
153. Allen IC, TeKippe EM, Woodford RM, Uronis JM, Holl EK, et al. The NLRP3 inflammasome functions as a negative regulator of tumorigenesis during colitis-associated cancer. J. Exp. Med. 2010; 207:1045--56. [PubMed: 20385749]

154. Zaki MH, Boyd KL, Vogel P, Kastan MB, Lamkanfi M, Kanneganti TD. The NLRP3 inflammasome protects against loss of epithelial integrity and mortality during experimental colitis. Immunity. 2010; 32:379--91. [PubMed: 20303296]

155. Dupaul-Chicoine J, Yeretssian G, Doiron K, Bergstrom KS, McIntire CR, et al. Control of intestinal homeostasis, colitis, and colitis-associated colorectal cancer by the inflammatory caspases. Immunity. 2010; 32:367--78. [PubMed: 20226691]

156. Dinarello CA. Immunological and inflammatory functions of the interleukin-1 family. Annu. Rev. Immunol. 2009; 27:519-50. [PubMed: 19302047]

157. Salcedo R, Worschech A, Cardone M, Jones Y, Gyulai Z, Dai RM, Wang E, Ma W, Haines D, O'HUigin C, Marincola FM, Trinchieri G. MyD88-mediated signaling prevents development of adenocarcinomas of the colon: role of interleukin 18. J Exp Med. 2010; 207:1625-36. [PubMed: 20624890]

158. Ghiringhelli F, Apetoh L, Tesniere A, Aymeric L, Ma Y, et al. Activation of the NLRP3 inflammasome in dendritic cells induces IL-1 $\beta$-dependent adaptive immunity against tumors. Nat. Med. 2009; 15:1170--78. [PubMed: 19767732]

159. Imaeda AB, Watanabe A, Sohail MA, Mahmood S, Mohamadnejad M, et al. Acetaminopheninduced hepatotoxicity in mice is dependent on Tlr9 and the Nalp3 inflammasome. J. Clin. Invest. 2009; 119:305--14. [PubMed: 19164858]

160. Chung Y, Chang SH, Martinez GJ, Yang XO, Nurieva R, et al. Critical regulation of early Th17 cell differentiation by interleukin-1 signaling. Immunity. 2009; 30:576--87. [PubMed: 19362022]

161. Sutton CE, Lalor SJ, Sweeney CM, Brereton CF, Lavelle EC, Mills KH. Interleukin-1 and IL-23 induce innate IL-17 production from $\gamma$ T cells, amplifying Th17 responses and autoimmunity. Immunity. 2009; 31:331--41. [PubMed: 19682929]

162. Wilson NJ, Boniface K, Chan JR, McKenzie BS, Blumenschein WM, et al. Development, cytokine profile and function of human interleukin 17-producing helper T cells. Nat. Immunol. 2007; 8:950--57. [PubMed: 17676044]

163. Acosta-Rodriguez EV, Napolitani G, Lanzavecchia A, Sallusto F. Interleukins $1 \beta$ and 6 but not transforming growth factor- $\beta$ are essential for the differentiation of interleukin 17-producing human T helper cells. Nat. Immunol. 2007; 8:942--49. [PubMed: 17676045]

164. Robinson D, Shibuya K, Mui A, Zonin F, Murphy E, et al. IGIF does not drive Th1 development but synergizes with IL-12 for interferon- $\gamma$ production and activates IRAK and NFkB. Immunity. 1997; 7:571--81. [PubMed: 9354477]

165. Gris D, Ye Z, Iocca HA, Wen H, Craven RR, et al. NLRP3 plays a critical role in the development of experimental autoimmune encephalomyelitis by mediating Th1 and Th17 responses. J. Immunol. 2010; 185:974--81. [PubMed: 20574004]

166. Shaw PJ, Lukens JR, Burns S, Chi H, McGargill MA, Kanneganti TD. Cutting edge: critical role for PYCARD/ASC in the development of experimental autoimmune encephalomyelitis. J. Immunol. 2010; 184:4610--4. [PubMed: 20368281]

167. Ippagunta SK, Brand DD, Luo J, Boyd KL, Calabrese C, et al. Inflammasome-independent role of apoptosis-associated speck-like protein containing a CARD (ASC) in T cell priming is critical for collagen-induced arthritis. J. Biol. Chem. 2010; 285:12454--62. [PubMed: 20177071]

168. Kolly L, Karababa M, Joosten LA, Narayan S, Salvi R, et al. Inflammatory role of ASC in antigen-induced arthritis is independent of caspase-1, NALP-3, and IPAF. J. Immunol. 2009; 183:4003-12. [PubMed: 19717512]

169. Ting JP, Duncan JA, Lei Y. How the noninflammasome NLRs function in the innate immune system. Science. 327:286-90. [PubMed: 20075243]

170. Lich JD, Williams KL, Moore CB, Arthur JC, Davis BK, Taxman DJ, Ting JP. Monarch-1 suppresses non-canonical NF-kappaB activation and p52-dependent chemokine expression in monocytes. J Immunol. 2007; 178:1256-60. [PubMed: 17237370] 
171. Cui J, Zhu L, Xia X, Wang HY, Legras X, Hong J, Ji J, Shen P, Zheng S, Chen ZJ, Wang RF. NLRC5 negatively regulates the NF-kappaB and type I interferon signaling pathways. Cell. 2010; 141:483-96. [PubMed: 20434986]

172. Kuenzel S, Till A, Winkler M, Hasler R, Lipinski S, Jung S, Grotzinger J, Fickenscher H, Schreiber S, Rosenstiel P. The nucleotide-binding oligomerization domain-like receptor NLRC5 is involved in IFN-dependent antiviral immune responses. J Immunol. 2010; 184:1990-2000. [PubMed: 20061403]

173. Neerincx A, Lautz K, Menning M, Kremmer E, Zigrino P, Hosel M, Buning H, Schwarzenbacher $\mathrm{R}$, Kufer TA. A role for the human nucleotide-binding domain, leucine-rich repeat-containing family member NLRC5 in antiviral responses. J Biol Chem. 2010; 285:26223-32. [PubMed: 20538593]

174. Moore CB, Bergstralh DT, Duncan JA, Lei Y, Morrison TE, et al. NLRX1 is a regulator of mitochondrial antiviral immunity. Nature. 2008; 451:573-77. [PubMed: 18200010]

175. Sabbah A, Chang TH, Harnack R, Frohlich V, Tominaga K, et al. Activation of the innate immune response by Nod2. Nat. Immunol. 2009; 10:10173-80. 


\section{SUMMARY POINTS}

1. The inflammasome is activated by a diverse battery of self- and foreign entities.

2. Host- and pathogen-derived inhibitors of the inflammasome act either to control inflammation or to facilitate infection

3. There are three models to explain inflammasome activation: $(a)$ induction by reactive oxygen species, $(b)$ lysosomal destabilization, or $(c)$ pore formation and $\mathrm{K}^{+}$efflux and possibly PAMP influx.

4. Inflammasome activation and chronic inflammation drive metabolic disease progression, contribute to carcinogenesis, and instruct the adaptive immune response. 


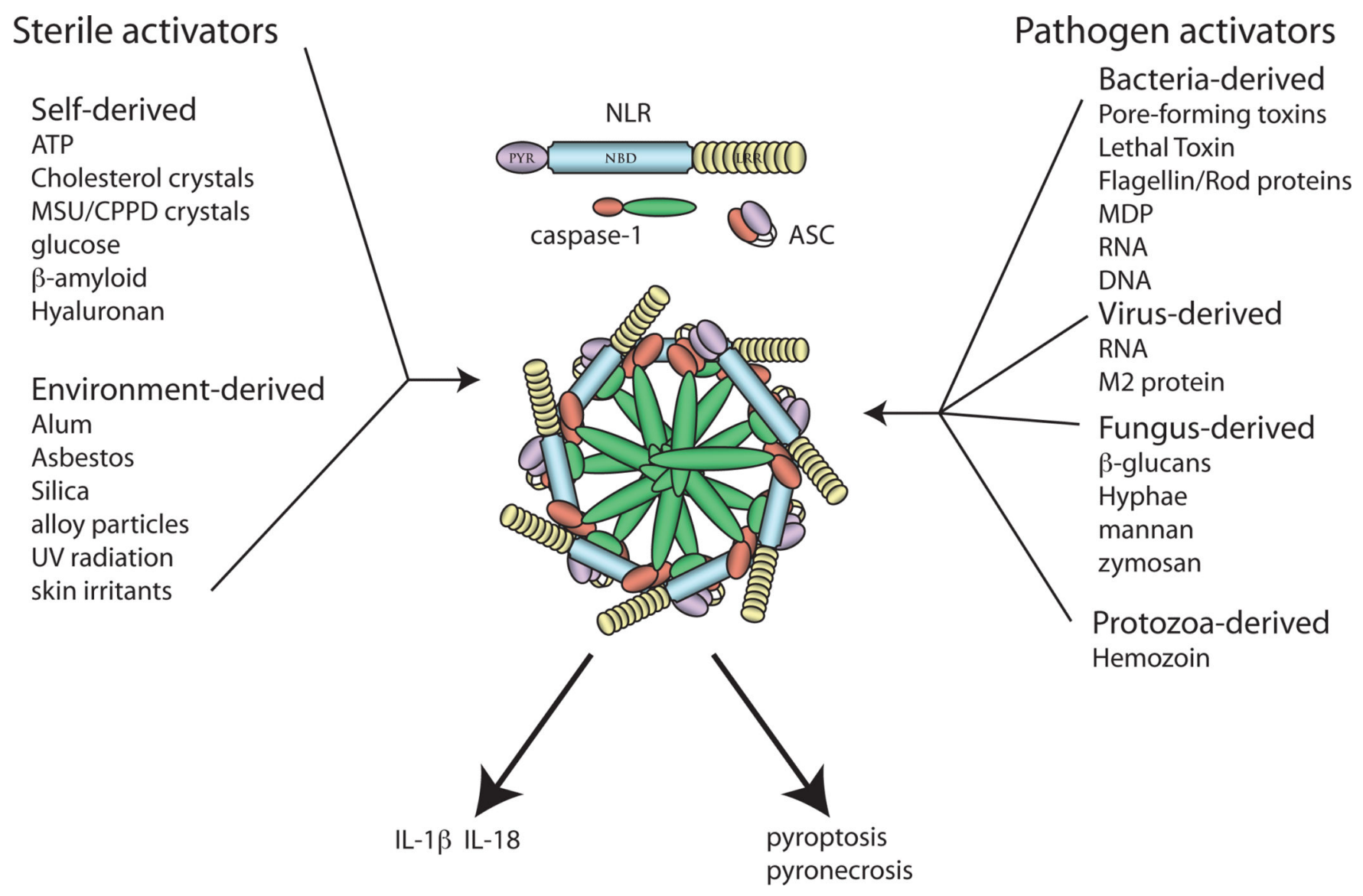

Figure 1.

Activators of the inflammasome. Activators of the inflammasome are divided into two categories: Sterile activators include host- and environment-derived molecules, and pathogen-associated activators include PAMPs derived from bacteria, virus, fungus, and protozoa. Assembly of the NLRs, ASC, and caspase-1 leads to the formation of a penta- or heptamer structure: the inflammasome. Activation of the inflammasome leads to maturation and secretion of IL- $1 \beta$ and IL-18 as well as inflammatory cell death, by either pyroptosis or pyronecrosis. 
Endogenous inhibitors

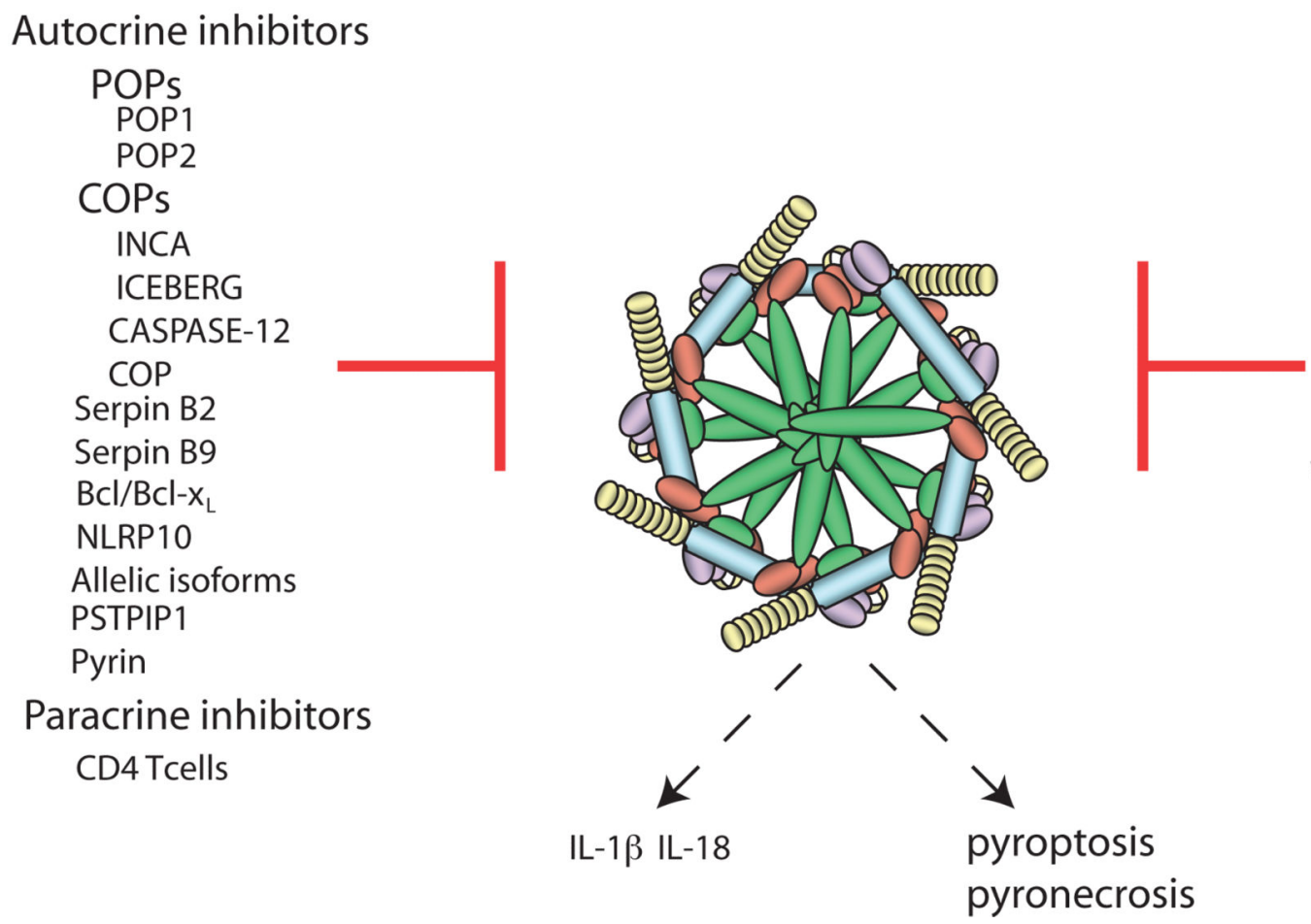

Exogenous inhibitors

Paracrine inhibitors

Yops

YopP

YopE

YopT

YopM

ESX-1

ExoU

Zmp1

Viral inhibitors

Serp2

CrmA

B13R

M013

gp013L

p35

NS1

\section{Figure 2.}

Models of inflammasome activation. Coordination of a manifold series of signals culminates in the activation of the inflammasome. Three models have been put forth to explain mechanisms of inflammasome activation. The observation that inflammasomes are activated by a diverse array of biological molecules suggests an indirect mechanism of sensing as opposed to a direct interaction with a receptor ligand pair. Reactive oxygen species (ROS) are induced by many of the known activators of inflammasomes. It is postulated that the generation of ROS, possibly via the phagosomal NADH-oxidase, releases thioredoxininteracting protein (TXNIP) from thioredoxin (TRX). TXNIP, which is free from TRX, can bind to NLRP3, possibly by competing with HSP90 and SGT1, which retain NLRP3 in an inactive state. The NLRP3 TXNIP complex facilitates inflammasome formation through an unknown mechanism that might relate to the activity of superoxide dismutase (SOD1). Alternatively, the release of cathepsin B (and possibly other cathepsins) due to lysosomal destabilization activates the inflammasome during phagocytosis. How cathepsin B activates the inflammasome is currently unknown, but activation requires its enzymatic activity. The final model posits pore formation at the plasma membrane that allows for $\mathrm{K}^{+}$efflux. Pore formation can occur via the $\mathrm{P} 2 \mathrm{X} 7$ receptor/pannexin-1 oligo-structure via pathogen toxins or ion channels. A modification to the last model suggests that small PAMPs can gain cytosolic access via the $\mathrm{P} 2 \mathrm{X} 7$ receptor/pannexin-1 hemichannel and activate the inflammasome. 


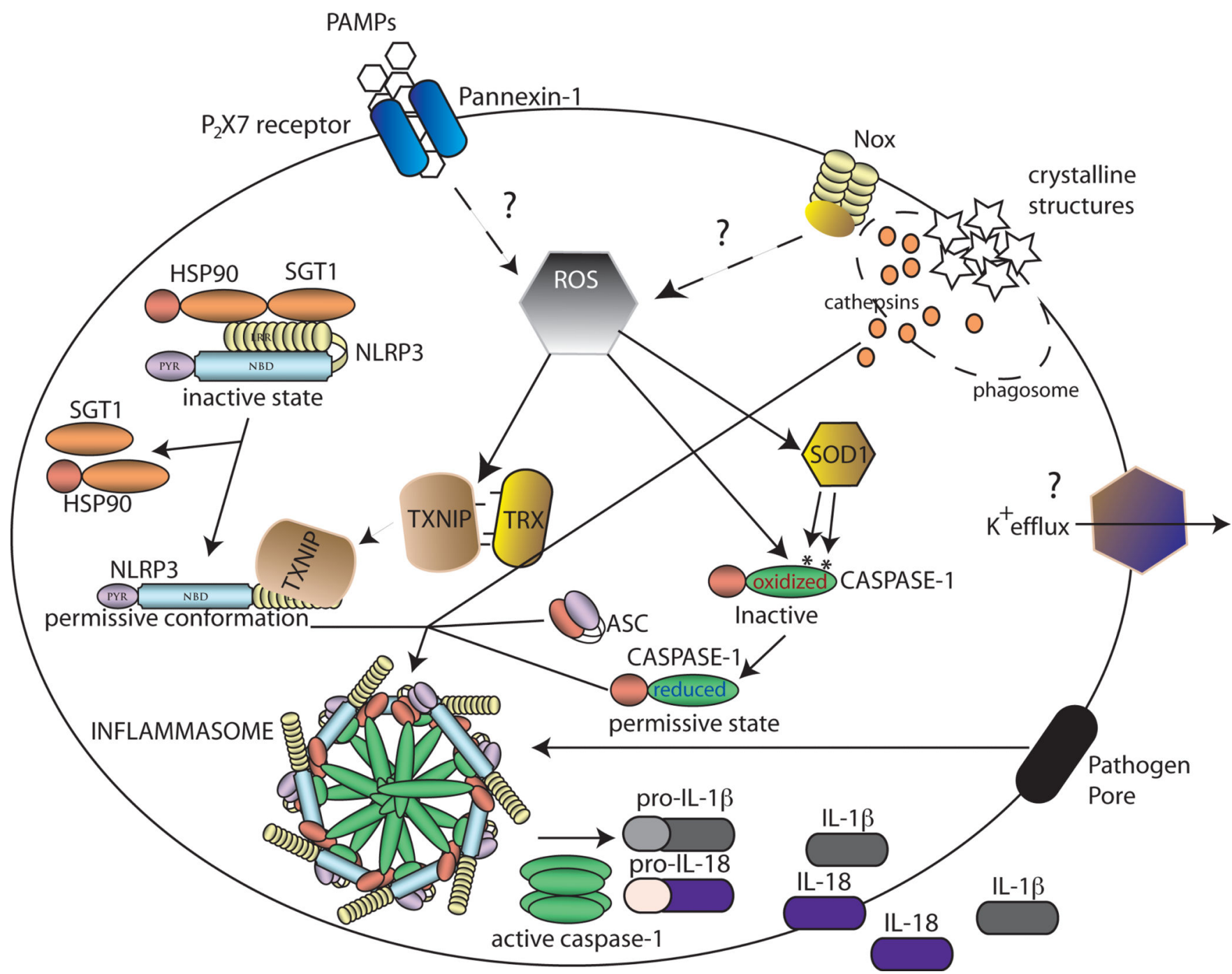

Figure 3.

Inhibitors of the inflammasome. Inhibitors of the inflammasome are divided into two categories: endogenous and exogenous. The inhibitors of the inflammasome are dynamic in nature. The molecular mechanisms that facilitate inhibition are poorly understood. Nonetheless, their existence underscores the importance of this pathway in controlling inflammation. 


\section{Primary event}

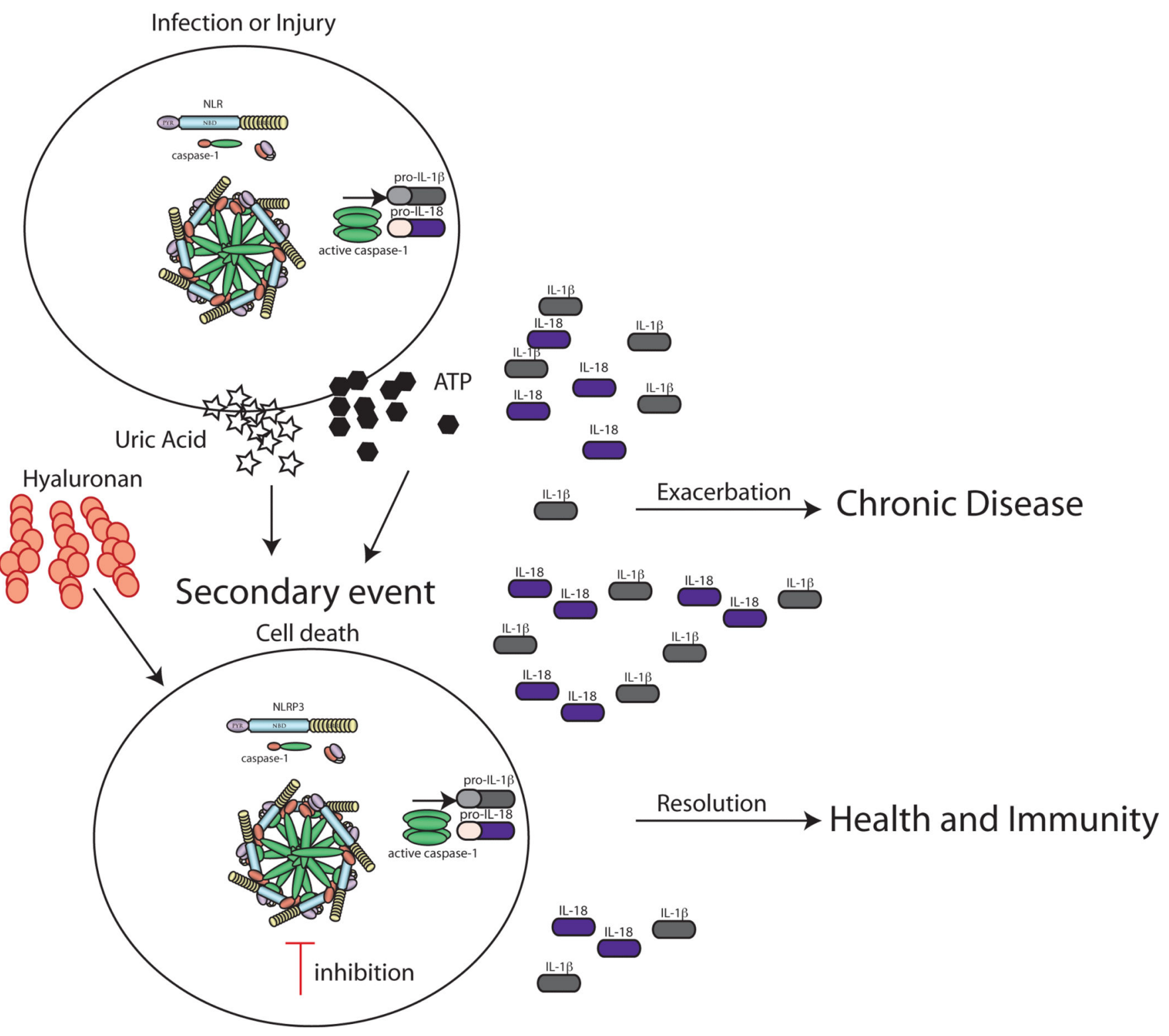

Figure 4.

In vivo activation of inflammasomes. During infection, injury, or sterile inflammation, the inflammasome becomes directly and indirectly activated. The initial event leads to caspase-1 activation, IL-1 $\beta$ and IL-18 secretion, and cell death. Cell death can release a second series of inflammasome agonists such as ATP, hyaluronan, and uric acid that can activate the inflammasome in a paracrine manner to augment the response. The elaboration of IL-1 $\beta$ and IL-18 contributes to the recruitment of additional effector cell populations. The perpetuation of the inflammatory cascade culminates either in resolution of inflammation and infection or in chronic inflammatory diseases. 